NBER WORKING PAPER SERIES

\title{
PRESCRIPTION DRUGS, MEDICAL CARE, AND HEALTH OUTCOMES: A MODEL OF ELDERLY HEALTH DYNAMICS
}

\author{
Zhou Yang \\ Donna B. Gilleskie \\ Edward C. Norton \\ Working Paper 10964 \\ http://www.nber.org/papers/w10964 \\ NATIONAL BUREAU OF ECONOMIC RESEARCH \\ 1050 Massachusetts Avenue \\ Cambridge, MA 02138 \\ December 2004
}

This research is funded by the National Institute on Aging Grant Number R01-AG16600. We appreciate comments from David Blau, Richard Hirth, Xin Li, Betsy Sleath, Sally Stearns, Morris Weinberger, and seminar and conference participants at the University of North Carolina at Chapel Hill, Michigan State University, the 4th World Congress of the international Health Economics Association, and the 15th Annual Health Economics Conference. We also acknowledge Tom Mroz for providing the discrete factor random effect subroutine that we adapted for estimation of our model. Comments are welcome at zyang@phhp.ufl.edu,donna_gilleskie@unc.edu, or edward_norton@unc.edu. The views expressed herein are those of the author(s) and do not necessarily reflect the views of the National Bureau of Economic Research.

(C) 2004 by Zhou Yang, Donna B. Gilleskie, and Edward C. Norton. All rights reserved. Short sections of text, not to exceed two paragraphs, may be quoted without explicit permission provided that full credit, including (C) notice, is given to the source. 
Prescription Drugs, Medical Care, and Health Outcomes: A Model of Elderly Health Dynamics Zhou Yang. Donna B. Gilleskie, and Edward C. Norton

NBER Working Paper No. 10964

December 2004

JEL No. I12, I18, H5

\begin{abstract}
$\underline{\text { ABSTRACT }}$
There is much debate about whether the Medicare Prescription Drug Bill - the greatest expansion of Medicare benefits since its creation in 1965 - will improve the health of elderly Americans, and how much it will cost. We model how insurance affects medical care utilization, and subsequently, health outcomes over time in a dynamic model with correlated errors. Longitudinal individual-level data from the 1992-1998 Medicare Current Beneficiary Survey provide estimates of these effects. Simulations over five years show that expanding prescription drug coverage would increase drug expenditures by between $12 \%$ and $17 \%$. However, other health care expenditures would only increase slightly, and the mortality rate would improve.
\end{abstract}

\title{
Zhou Yang
}

Department of Health Services Research, Management and Policy

University of Florida

Gainesville, FL 32611-7140

zyang@phhp.ufl.edu

Donna B. Gilleskie

Department of Economics

University of North Carolina at Chapel Hill

CB\#3305, Gardner Hall

Chapel Hill, NC 27599-3305

and NBER

donna_gilleskie@unc.edu

Edward C. Norton

Department of Health Policy and Administration

University of North Carolina at Chapel Hill

CB\#7411, 1101C McGavran-Greenberg Hall

Chapel Hill, NC 27599-3305

edward_norton@unc.edu 


\section{Introduction}

In November 2003, Congress passed the Medicare Prescription Drug Bill in the greatest expansion of Medicare benefits since its creation in 1965. Despite passage of this landmark legislation, policymakers and researchers fiercely debate two unanswered questions about the Drug Bill. Will it improve the health of elderly Americans? And what will it cost? Proponents of the Drug Bill argue that higher outpatient prescription drug utilization will improve the health status of Medicare beneficiaries. Opponents are concerned that prescription drugs will have little effect on morbidity and mortality. As for the cost, there is no consensus regarding the appropriate methodology for cost estimation, so not surprisingly cost estimates for the new drug benefit program vary considerably. Legislators who opposed the Drug Bill complained that the original budget projection of $\$ 400$ billion over ten years was too high. Then, in February 2004, the White House revised the budget estimate to an even higher amount of $\$ 540$ billion.

If proponents are correct that increased prescription drug use will improve health, then short-run medical care expenditures may fall, particularly if inpatient hospital stays are avoided. Over time, however, decreased mortality could increase lifetime medical care use. Investments in health today affect future health status and expenditures (Grossman, 1972). It is this complicated relationship among medical care use and morbidity and mortality over time that we explore in our research.

Most health economic studies addressing this policy issue measure the direct effect of drug insurance on demand for prescription drugs at a point in time. This approach results in a static cost estimate of the drug benefit. However, projections of long-run costs associated with drug coverage should reflect not only the immediate moral hazard effects (increased demand for drugs), but also short- and long-run changes in morbidity and mortality associated with changes in both drug and other medical care utilization over time (substitutes or com-

plements). Increased prescription drug use may improve Medicare beneficiaries' health, lower the disability rate, and decrease mortality (Philipson and Becker, 1998). Improved health and lower disability rates may in turn lead to reduced hospitalization (a Medicare Part A expense) and physician services (a Medicare Part B expense) in the short run. Decreased mortality, however, increases the Medicare-covered population and the potential demand for 
Medicare-covered services in the long run. Those individuals who might otherwise die if unable to purchase drug medication may survive with drug coverage. However, these marginal survivors may have reduced functional status and greater health care needs, complicating interpretation of the health benefits of drug coverage. Cost projections from studies that fail to measure the morbidity and mortality consequences of the increased consumption of drugs as well as the use of other medical care services may over or under estimate the net financial cost of the policy change.

We demonstrate that a fuller understanding of these issues begins with a dynamic behavioral analysis that allows the increase in prescription drug utilization induced by more generous drug coverage to affect subsequent (total) health care expenditures of the elderly through changes in health status over time. We use data from the longitudinal Medicare Current Beneficiary Survey Data (MCBS) from 1992 to 1998 to jointly estimate a system of empirical equations representing supplemental insurance coverage, dynamic drug and other medical care demand, and health production. More specifically, our findings quantify the effect of drug coverage (through Medicaid or employer and private insurance plans) on prescription drug use among Medicare beneficiaries, the effect of drug use on functional status and mortality, and the effect of drug use and health on the subsequent demand for drugs as well as Medicare Part A (hospitalization) and Part B (physician) services over time. We simulate the long-run (5 year) effect of increased drug coverage by incorporating behavioral responses to the policy change year by year. We show that with universal coverage of drugs prescription drug expenditures in our sample would rise between 12.2 and $17.5 \%$ over 5 years, while inpatient care and physician services use increase only slightly. Much of this increase due to the induced changes in the composition of health. Long-run survival probabilities increase, leading to larger proportions of elderly survivors with functional limitations. Our projections, however, are smaller than those produced by extrapolating static models that fail to incorporate the dynamic consequences of increased drug use on health outcomes and other Medicare-covered services use.

This paper fills a large void in the policy debate about the Medicare prescription drug benefit, as well as in the health economics literature, by investigating the dynamic nature of elderly health care behavior and simulating the long-term effect of prescription drug coverage 
on the health outcomes of the elderly and the total cost to Medicare. Dynamic behavioral models are appropriate when studying complex behavior over time where changes in the composition of individual characteristics is associated with the behavior of interest. Fortunately, our longitudinal data are sufficiently rich in both health and expenditure information to estimate the dynamic empirical model. We use the results from estimation of the model to answer the policy questions, not only for the sample as a whole, but also for interesting subpopulations defined, for example, by specific health outcomes.

\section{Background and Literature Review}

Even without Medicare prescription drug coverage, elderly Americans (age 65 and older) spend a large amount on outpatient prescription drugs. In 1995, approximately 85 percent of the noninstitutionalized elderly had at least one prescription, and the average annual outpatient prescription drug expenditure was around $\$ 600$ per person and $\$ 22$ billion in total (Poisal et al., 1999). Although the elderly only account for one-eighth of the total population, their drug expenditures account for one-third of all drug expenditures in the U.S. (DHHS, 1998; Long, 1994). Elderly persons have greater demand for prescription drugs because of worse general health, higher disability rates, and a higher prevalence of chronic diseases (Adams et al., 2001a; Blustein, 2000; Johnson et al., 1997; Lillard et al., 1999; Poisal et al., 1999; Rogowski et al., 1997; Soumerai and Ross-Degnan, 1999; Stuart and Coulson, 1994).

Despite the high demand, insurance coverage of outpatient prescription drugs is limited among the elderly. Before 2003, the Medicare program did not cover most outpatient prescription drugs. However, about $65 \%$ of Medicare beneficiaries have some drug coverage from at least one supplemental insurance plan, leaving 35\% who must cover the full cost of outpatient prescription drugs out of pocket. Among those with drug coverage (which may be from multiple sources), about $44 \%$ have employer-provided health insurance (either as retirees or active workers), $16 \%$ hold privately-purchased individual coverage, $16 \%$ have Medigap insurance, $11 \%$ are covered through a Medicare HMO, 17\% are on Medicaid, and $4 \%$ have other publicly-provided coverage, including Veteran Assistance or state Pharmacy Assistance (Poisal et al., 1999). Adverse selection suggests, however, that those who 
purchase additional insurance beyond Medicare are those who expect to have higher than average expenditures.

Although more than half of the Medicare beneficiaries have at least one type of drug coverage, none of these drug insurance plans are comprehensive. Out-of-pocket payment is still the largest source of outpatient drug payment for the elderly, and accounts for $50 \%$ of total drug expenditures (Poisel et al., 1999). Several studies show that lack of sufficient insurance coverage is one major reason for under-use of prescription drugs. Steinman and colleagues (2001) found that, among elderly people age 70 and older in the U.S., chronically ill patients without drug insurance were more likely to skip doses or avoid using medication than those with drug insurance. Federman and colleagues (2001) found that, among Medicare beneficiaries with coronary heart disease, those without drug insurance have lower use of statins, which is a class of expensive and effective cardiovascular drugs, compared with those who have prescription drug insurance. Poisal and Murray (2001) found that elderly Medicare beneficiaries with drug coverage received $9 \%$ more prescriptions on average over one year, while those without any drug coverage received $2.4 \%$ fewer prescriptions. Even among those Medicare beneficiaries who have drug insurance, high copayment rates or other cost-sharing limitations may restrict the appropriate use of clinically-essential drugs (Reeder and Nelson, 1985; Soumerai et al., 1987; Soumerai and Ross-Degnan, 1990; Soumerai et al., 1991; Soumerai et al., 1994).

Most studies of the potential costs of a Medicare prescription drug benefit are crosssectional and provide a point-in-time correlation between drug coverage and drug utilization. These studies suggest that insurance increases prescription drug use, and the more generous plans have the strongest positive effects (Adams et al., 2001b; Blustein, 2000; Lillard et al., 1999; Long, 1994; Poisal et al., 1999; Rogowski et al., 1997). Other cross-sectional studies conducted at the state or community level draw similar conclusions (Fillenbaum et al., 1993; Stuart and Coulson, 1993; Stuart and Grana, 1995).

To better understand the effects of increased drug coverage among the elderly, it is necessary to consider both the effect of insurance on drug use, as well as the effect of drug use on other health care costs and health outcomes. With regard to the effect of drug use on non-drug health expenditures, Soumerai and colleagues (1991) found that a reduction 
in use of outpatient drugs due to a prescription cap in New Hampshire led to increased hospital and nursing home admission rates among elderly beneficiaries over one year. For mentally ill patients, the increase in the cost of non-drug medical services even exceeded the savings in reduced prescription drug use (Soumerai et al., 1994). A study conducted in Canada revealed that greater consumer cost-sharing for prescription drugs led to a reduction in consumption of essential drugs, and higher rates of adverse health events and emergency room visits among elderly persons (Tamblyn et al., 2001). These studies, however, do not consider explicitly the effect of altered drug use on patient mortality or morbidity.

Turning to the effect of drug use on health outcomes, Gowrisankaran and Town (2004) analyzed county-level mortality rates over time and found that greater enrollment in Medicare managed care insurance plans without a drug benefit was associated with higher mortality but found no association between mortality and Medicare managed care plans with drug coverage. Federman et al. (2001) and Lichtenberg (2003) found that greater use of clinically-essential drugs or newer drugs may decrease the population mortality rate. None of these studies, however, investigate morbidity and functional status among the survivors and their subsequent health care expenditures. Some researchers argue that chronic diseases are the main reason for functional disability and therefore suggest that the development and use of new drugs could decrease disability rates (Cutler, 2001; Ferrucci and Guralnik, 1997).

Measurement of the effect of drug use on health outcomes (both mortality and morbidity) over time is necessary for predicting the net cost of a Medicare drug benefit. For example, studies that fail to consider the possible reduction in disability rates due to drug use may overstate the net cost of the drug benefit given the positive correlation between disability and inpatient care expenditures among the elderly (Stearns et al., 2003). If the elderly live longer but healthier lives, then the total medical care cost at the population level may not necessarily increase. Alternatively, studies that fail to consider how drug use affects morbidity and mortality may understate the long-term net costs of a Medicare drug benefit. A lower mortality rate and greater longevity will increase the number of Medicare beneficiaries and lead to greater demand for all Medicare-covered health care services. Additionally, the distribution of health among survivors changes: increased survival may imply a larger proportion of disabled elderly. There is a large void in the existing literature, and 
a striking omission of longitudinal analyses of individual behavior, that could explain the complicated causal relationship between drug utilization, changes in health status, and subsequent expenditures on other medical care services among the elderly population (Adams et al., 2001a). This paper seeks to fill the void.

\section{Model of Elderly Health Dynamics}

\subsection{Empirical Framework}

To understand the impact of insurance on elderly medical care consumption decisions, we model annual individual utilization and health transitions over time. Our empirical model allows outpatient prescription drug use to be related to other medical care use both directly (as a substitute or complement) and indirectly (as it affects health over time). Our model has four key features: 1) observed supplemental prescription drug coverage decisions depend on unobserved individual characteristics that also influence the demand for prescription drugs (endogenous insurance coverage), 2) current consumption of different types of medical care may be correlated (joint estimation of different medical care services), 3) current medical care consumption influences future health which also determines future consumption (joint estimation of medical care inputs and health outcomes), and 4) past medical care consumption influences current consumption partially through pathways other than health (direct effects of lagged behavior). We discuss each of these components of the model in turn.

Supplementation of Medicare coverage with prescription drug insurance is a choice. We assume that all elderly persons (age 65 and older) are eligible for Medicare (and virtually all elect both Part A and Part B Medicare coverage in our data). We categorize supplemental health insurance coverage as either Medicaid (which covers prescription drugs), any private insurance with a drug benefit, or any private insurance without a drug benefit. We allow the observed supplemental health insurance coverage, $I_{t}$, of an individual to be influenced by unobservable individual characteristics (e.g., health history, preferences for care) that also influence medical care decisions and health transitions. Assumed exogeneity of drug coverage would bias estimates of its effect on drug consumption if such adverse selection occurs. Correct estimates of this effect are crucial for evaluating the costs and benefits of prescription drug coverage. 
While this study focuses on how drug coverage affects prescription drug use, we cannot ignore the correlated use of other medical services such as hospital and physician care. These different types of medical care may be complements to or substitutes for prescription drug use. That is, a hospital stay may require physician care follow-ups exhibiting positive contemporaneous correlation in (annual) use. Alternatively, prescription drug use may prevent, delay, or substitute for costly hospitalization reflecting negative contemporaneous correlation. Hence, we jointly model the per-year demand for prescription drugs, $D_{t}$; hospitalization (Medicare Part A), $A_{t}$; and physician services (Medicare Part B), $B_{t}$. Our empirical treatment of possible correlation among contemporaneous unobservables is discussed later.

In each year, $H_{t}$ represents health status at the beginning of the annual observation period $t$. In the empirical model health status is defined by functional limitations. Given her observed health status, an individual optimally chooses a level of outpatient prescription drug utilization, $D_{t}$, and utilization of other forms of medical care, $A_{t}$ and $B_{t}$. Her objective is to maximize the value of current period health-state dependent utility (of medical care consumption and consumption of other goods) subject to her budget constraint and out-of-pocket costs plus the discounted present value of future utility given uncertainty about health transitions. Current health and medical care inputs determine health in the subsequent period through a health production function. Hence, one empirical objective is to quantify the effect of endogenous and interrelated health care choices on future health. This Grossman-like dynamic health production function is essential for linking current consumption behavior with future health (and indirectly, future medical care utilization) and thus appropriately predicting net costs of expanded drug coverage.

Finally, our model allows for a direct relationship between medical care consumption in successive years in addition to the indirect relationship exhibited through annual health transitions. That is, previous health care use may directly affect the marginal utility of current medical care alternatives independent of the effect of prior medical care use on health outcomes. For example, some Medicare beneficiaries develop stable and trustworthy relationships with their outpatient care physicians over time. An individual with more physician contact (or a regular source of care), all else equal, may be more likely to fill 
prescriptions and use other forms of medical care in the future because of the relationship that has been established between patient and provider. Hence, we allow past medical care use to influence current medical care use. It is important, however, to appropriately model serial correlation in individual unobservables that might lead to an apparent statistical correlation in use across time. A major concern is accurately modeling unobserved health since the health measures available in the data may not fully capture the effects of past medical care utilization through the health production function. Failing to account for unobserved heterogeneity would incorrectly attribute significance to lagged consumption behavior.

It remains to test these implications empirically.

\subsection{Empirical Specification}

We begin by specifying equations for the dynamic medical care utilization and health outcomes of individuals over time. The observed heterogeneity in our set of equations includes endogenous health status, $H_{t}$; supplemental insurance coverage, $I_{t}$; and past medical care consumption $\left(D_{t-1}, A_{t-1}, B_{t-1}\right)$. We also indicate any hospitalization in the fourth quarter of the previous year by $Q_{t-1}$ because medical care demand in adjacent years might be more highly correlated immediately following a hospitalization (i.e., in the next quarter). Addition-

ally, exogenous permanent and time-varying demographic information, $X_{t}$, and exogenous health shocks, $S_{t}$, influence observed outcomes. We hold discussion of the unobserved heterogeneity that leads to correlation in unobservables across equations to the next subsection after the basic model has been described.

The distributions of prescription drugs and hospital expenditures are highly skewed, with some people having zero expenditures. Therefore, current expenditures of these two types of medical care are modelled in two parts. The first part employs a logit model to estimate the probability of any expenditures $\left(e_{t}>0\right)$. That is,

$$
\begin{aligned}
\operatorname{Pr}\left(e_{t}>0\right)= & \frac{\exp \left(\alpha Y_{t}\right)}{1+\exp \left(\alpha Y_{t}\right)} \\
\text { where } e_{t}= & \alpha Y_{t}+u_{t}^{e} \\
= & \alpha_{e 0}+\alpha_{e 1} H_{t}+\alpha_{e 2} I_{t}+\alpha_{e 3} D_{t-1}+\alpha_{e 4} A_{t-1}+\alpha_{e 5} B_{t-1} \\
& +\lambda_{e}\left[\alpha_{e 6} \mathbf{1}\left(A_{t-1}>0\right)+\alpha_{e 7}\left(\mathbf{1}\left(A_{t-1}>0\right) \cdot Q_{t-1}\right)\right]
\end{aligned}
$$




$$
\begin{aligned}
& +\alpha_{e 8} X_{t}+\alpha_{e 9} S_{t}+u_{t}^{e}, \\
& (e=(D, A) ; \quad \lambda=1 \text { if } e=D ; \quad \lambda=0 \text { if } e=A) .
\end{aligned}
$$

The second part uses a linear model to estimate the log of expenditures conditional on positive expenditures. Because almost every Medicare beneficiary uses some physician services each year, only one equation representing the log of total Part B expenditures is estimated. Thus,

$$
\begin{aligned}
\ln \left(e_{t} \mid e_{t}>0\right)= & \delta_{e 0}+\delta_{e 1} H_{t}+\delta_{e 2} I_{t}+\delta_{e 3} D_{t-1}+\delta_{e 4} A_{t-1}+\delta_{e 5} B_{t-1} \\
& \lambda_{e}\left[\delta_{e 6} \mathbf{1}\left(A_{t-1}>0\right)+\delta_{e 7}\left(\mathbf{1}\left(A_{t-1}>0\right) \cdot Q_{t-1}\right)\right] \\
& +\delta_{e 8} X_{t}+\delta_{e 9} S_{t}+u_{t}^{e}, \\
& \left(e=B ; \quad e=(A, D) \text { if } e_{t}>0 ; \quad \lambda=1 \text { if } e=D ; \quad \lambda=0 \text { if } e \neq D\right) .
\end{aligned}
$$

The index function $\mathbf{1}(\cdot)$ equals one when the endogenous previous behavior in parenthesis is true and is zero otherwise. The vectors of estimated parameters on observable covariates are $\alpha$ and $\delta$.

Health transitions are determined by a health production function. The specification is dynamic because of its dependence on the endogenous lagged values of health and medical care expenditures. Health is measured as a 6-category outcome representing worsening health, with death as the extreme negative health outcome. Using a multinomial logit model, the health production function is

$$
\begin{aligned}
\operatorname{Pr}\left(H_{t+1}=h\right)= & \frac{\exp \left(\gamma_{h} Y_{t}\right)}{\sum_{h^{\prime}=1}^{6} \exp \left(\gamma_{h^{\prime}} Y_{t}\right)} \\
\text { where } \gamma_{h} Y_{t}= & \gamma_{h 0}+\gamma_{h 1} H_{t}+\gamma_{h 2} A_{t}+\gamma_{h 3} B_{t}+\gamma_{h 4} D_{t}+\gamma_{h 5} D_{t}^{2} \\
& +\gamma_{h 6} X_{t}+\gamma_{h 7} S_{t} \\
& +\gamma_{h 8}\left(D_{t} \cdot H_{t}\right)+\gamma_{h 9}\left(D_{t}^{2} \cdot H_{t}\right) \\
& +\gamma_{h 10}\left(D_{t} \cdot X_{t}\right)+\gamma_{h 11}\left(D_{t}^{2} \cdot X_{t}\right) \\
& +\gamma_{h 12}\left(A_{t} \cdot H_{t}\right)+\gamma_{h 13}\left(B_{t} \cdot H_{t}\right) \\
& +\gamma_{h 14}\left(A_{t} \cdot X_{t}\right)+\gamma_{h 15}\left(B_{t} \cdot X_{t}\right)
\end{aligned}
$$

The vector of covariate parameters, $\gamma$, is estimated jointly with the parameters in equations 1 and 2 . 
For reasons explained in the data section, we do not model changes in health insurance over time (e.g., switching, adding, or dropping coverage). As such, the period $t=1$ polydichotomous supplemental insurance choices are modeled in reduced form as multinomial logit outcomes where

$$
\begin{aligned}
\operatorname{Pr}\left(I_{1}=i\right) & =\frac{\exp \left(\eta_{i} Y_{1}\right)}{\sum_{i^{\prime}=1}^{3} \exp \left(\eta_{i^{\prime}} Y_{1}\right)} \\
\text { and } \eta_{i} Y_{1} & =\eta_{i 0}+\eta_{i 1} X_{1}+\eta_{i 2} Z_{1}
\end{aligned}
$$

The variables $Z_{1}$ affect the insurance choice only and are uncorrelated with $X_{1}$. Five additional reduced-form equations explain the initial health status and expenditures that are observed in the first period of the data. These initial observations cannot be explained using specifications 1, 2, or 3 because lagged values of important variables are not observed in this first period. All of these initial observations, however, may be correlated with subsequent observations through unobserved heterogeneity that we discuss next.

\subsection{Unobserved Individual Heterogeneity}

Each of the main equations representing medical care demand and health production (Equations 1, 2, and 3) along with reduced form equations for initially observed insurance coverage, health status, and expenditures (6 additional equations), has an associated error term that captures differences in behavior that cannot be explained by observed differences across individuals or over time. These unobserved individual characteristics likely influence many or all of the behaviors we model. To allow for this correlation, we estimate the set of equations jointly rather than separately. Our empirical framework incorporates two specific types of unobserved heterogeneity. One type is permanent individual heterogeneity, such as unobserved attitudes toward medical treatment or quality of health care providers. For example, a patient who prefers outpatient care to inpatient care is more likely to seek drug treatment than a patient who better tolerates inpatient care. Similarly, he may choose supplemental insurance with better prescription drug coverage.

The other type of unobserved heterogeneity is time-varying heterogeneity. The time unit of analysis in this study is a calendar year. Within this time frame the health status 
of Medicare beneficiaries may change significantly. Although the health production function helps to explain health transitions over a year, other unobserved factors also influence changes in health status. An example of an unobserved characteristic that varies over time for a particular individual is the unobserved rate of natural deterioration of health. Although medical care consumption may help people maintain good health, the health status of elderly people deteriorates naturally because of aging, and more importantly, at different rates for different people. It is difficult to obtain empirically the theoretical result that medical care utilization improves health outcomes because greater utilization is typically observed by individuals in poorer health. Hence it is important to control for time-varying unobserved individual heterogeneity. Similarly, unobserved time-varying shocks to one's health might explain simultaneous correlation between different types of medical care demand.

Let $u_{t}^{e}$ denote the unobserved error term associated with outcome $e(e=A, B, D, H$, or $I)$ at time $t(t=1,2, \ldots, T)$. In order to control for unobserved individual heterogeneity, we decompose the error term of each equation into three components. The first part, $\mu$, captures permanent, or time-independent, unobserved individual heterogeneity; the second part, $\nu_{t}$, controls for time-varying unobserved individual heterogeneity; and the third part, $\varepsilon_{t}^{e}$, is a serially uncorrelated error term for equation $e$. Let $\rho_{e}$ be the factor loading on $\mu$ for equation $e$ and $\omega_{e}$ be the factor loading on $\nu_{t}$. The error decomposition is

$$
u_{t}^{e}=\rho_{e} \mu+\omega_{e} \nu_{t}+\varepsilon_{t}^{e}
$$

where $\rho_{e}, \mu, \omega_{e}$, and $\nu_{t}$ are estimated parameters in the empirical model. Note that $\rho_{H}$ and $\rho_{I}$ are vectors of parameters for each estimated outcome $H_{t}=h$ and $I_{1}=i$. One could think of $\rho \mu$ as an individual fixed effect and $\omega \nu_{t}$ as a time-varying effect. The notation chosen, however, is specific to the estimation strategy (described below) used to model and estimate these two types of heterogeneity.

We treat the unobserved heterogeneity $\left(\mu\right.$ and $\left.\nu_{t}\right)$ as discrete random effects and integrate them out of the model (see Heckman and Singer (1983) and Mroz (1999) for analyses comparing this procedure and others). This method of allowing correlation in unobservables across multiple equations without imposing a distributional form has been used in a wide variety of empirical applications including health (Goldman, 1995; Cutler, 1995; Blau and 
Gilleskie, 2001; Mays and Norton, 2000; Mello, Stearns, and Norton, 2002), welfare participation (Hoynes, 1996), child care (Blau and Hagy, 1998; Hu, 1999), disability insurance (Kreider and Riphahn, 2000), and program evaluation (Angeles et al., 1998). Different from the fixed effect or the general random effect approach, the discrete random effect approach assumes error terms in the correlated equations have discrete distributions of several mass points of support $\mu_{m}$ and an accompanying probability weight $\theta_{m}, m=1, \ldots, M$, where $M$ is determined empirically. Analogously, the points of support of the time-varying heterogeneity, $\nu_{k t}$, and the probability weights, $\psi_{k}, k=1, \ldots, K$, are estimated (with the appropriate normalizations for identification). This approach models the common heterogeneity that affects health expenditures, health outcomes, insurance coverage, and initial conditions. The approach is more efficient than a fixed effect approach that requires estimation of $N-1$ additional parameters, where $N$ is the total number of individuals in the sample. Additionally, there is no distributional assumption imposed on the error terms $\mu$ and $\nu_{t}$ and, hence, the method minimizes possible estimation bias from the stronger assumption of a specific error term distribution, such as joint normality, which is commonly assumed in models of joint behavior (Mroz, 1999). The likelihood function is

$$
\begin{aligned}
L= & \prod_{n=1}^{N}\left\{\sum_{m=1}^{M} \theta_{m} \prod_{j=1}^{4} \operatorname{Pr}\left(I_{n 1}^{j}=1 \mid \mu_{m}\right)^{I_{n 1}^{j}}\right. \\
\prod_{t=2}^{T_{n}}\left[\sum_{k=1}^{K} \psi_{k}\right. & \operatorname{Pr}\left(D_{n t}=0 \mid \mu_{m}, \nu_{k t}\right)^{\mathbf{1}\left(D_{n t}=0\right)} \cdot\left[\left(1-\operatorname{Pr}\left(D_{n t}=0\right) \mid \mu_{m}, \nu_{k t}\right) \cdot \phi_{D}\left(\cdot \mid \mu_{m}, \nu_{k t}\right)\right]^{\mathbf{1}\left(D_{n t}>0\right)} \\
& \cdot \operatorname{Pr}\left(A_{n t}=0 \mid \mu_{m}, \nu_{k t}\right)^{\mathbf{1}\left(A_{n t}=0\right)} \cdot\left[\left(1-\operatorname{Pr}\left(A_{n t}=0\right) \mid \mu_{m}, \nu_{k t}\right) \cdot \phi_{A}\left(\cdot \mid \mu_{m}, \nu_{k t}\right)\right]^{\mathbf{1}\left(A_{n t}>0\right)} \\
\cdot & \phi_{B}\left(\cdot \mid \mu_{m}, \nu_{k t}\right) \\
& \left.\left.\cdot \prod_{h=1}^{6} \operatorname{Pr}\left(H_{n t+1}=h \mid \mu_{m}, \nu_{k t}\right)^{H_{n t+1}^{h}}\right]\right\}
\end{aligned}
$$

Density functions for expenditures are denoted by $\phi_{e}(\cdot), e=D, A$, and $B$. The likelihood function includes the probability of supplemental health insurance coverage in period $t=1$ as the only estimated initial condition. We actually estimate five additional reduced-form equations in the initial period to capture health and the probability of any Medicare Part A expenditures and any prescription drug expenditures, as well as the log expenditures on drugs (conditional on any) and the log expenditures on Medicare Part B services. These initial condition equations are necessary because equations in the subsequent period depend 
on their endogenous lagged values. These additional equations are estimated jointly with the other equations and correlated through the unobserved permanent individual heterogeneity.

\subsection{Identification}

Identification in this system of equations is straightforward following the arguments of Bhargava and Sargan (1983) and Arellano and Bond (1991). Estimation of dynamic equations with panel data requires exogeneity of some of the explanatory variables conditional on the unobserved individual heterogeneity. Thus, all lagged values of exogenous variables serve to identify the system. Similarly, conditional on the unobserved heterogeneity $\left(\mu\right.$ and $\left.\nu_{t}\right)$, lagged values of the endogenous variables also aid identification assuming there is no serial correlation in the remaining errors. Additionally, we include some exogenous variables in the reduced-form specification of the initial conditions that do not independently affect the perperiod equations. These include height, which serves to measure health during childhood, and many detailed self-reported health conditions. Height is jointly significant in the initial condition equations, and is found to be insignificant when included in the main equations. Our specification of the permanent and time-varying unobserved heterogeneity also serves to identify the system, allowing all lagged i.i.d. errors to independently influence current behavior (e.g., through inclusion of lagged health in the expenditure equations).

\section{Description of Data}

The Medicare Current Beneficiary Survey (MCBS) is well suited for estimating our dynamic model. The MCBS is a longitudinal survey conducted by the Center for Medicare and Medicaid Services. Information in the MCBS is provided in two major parts - the survey files and the events files. Each respondent of the sample was surveyed three times a year and follow for multiple years. At the first interview, the respondents answered questions about their demographics, insurance and health status, including their functional status and chronic conditions. After the first interview, the respondents were asked to keep the receipts of all their medical bills subsequent to the first interview. The bills were then collected to keep track of use and cost information. At the end of each year, usually between September and December, respondents re-answered questions about their health status to record changes 
in their health. The events files include the date, charge and payment information of each inpatient, outpatient, medical provider, nursing home, home health and hospice event since the first interview and is based on claims data. The charge and payment information of each prescription or refill are also recorded, but the exact date of each prescription or refill is not available.

Our study uses the MCBS files from 1992 to 1998. As part of a longitudinal survey, the respondents were followed for up to five years. This longitudinal feature of MCBS makes it possible to estimate the effect of drug utilization in one year on subsequent health outcomes and medical care utilization in the next year. However, not all of the respondents in the sample were followed for the same number of years. Some of them died or dropped out during the survey period. Additionally, new individuals were brought into the survey each year allowing the sample size to be relatively similar across time.

The unit of analysis in our model is a person year. In order to focus on elderly Medicare beneficiaries, we first exclude respondents under age 65. After this initial exclusion, 25,208 unique individuals remain in the sample. Because expenditures on outpatient prescription drugs are not available from the MCBS for people who lived in long-term care facilities, we exclude 3,740 people who lived in a nursing home at any time during the survey period. Of these, almost $60 \%$ were continuously institutionalized throughout the observation period, and hence, do not contribute to our analysis. We avoid complicating the model further by ignoring the $6 \%$ of the elderly sample who enter a nursing home during our sample period rather than modeling this type of attrition from the sample. Because few individuals switch, add, or drop supplemental insurance coverage, we exclude those observed to change insurance coverage over time (7\% of respondents during our sample period). This allows us to avoid modeling the rare event of changing supplemental insurance coverage, yet we still model the endogeneity of the initially-observed supplemental insurance coverage. Future work will explore incorporating these two sources of endogenous selection.

Table 1 shows the sample distribution of the data by number of years followed and by calendar year. Among the 19,980 unique people with data available for our purposes, 14,439 were surveyed for more than one year. Because observations in an individual's first year of the survey define his or her initial conditions, only individuals who are followed for at 
least two years are used in estimation. The final sample of 14,439 people contributes 42,174 person-year observations used to estimate the per-period expenditures and health outcomes.

The average annual outpatient prescription drug expenditure (conditional on any) was $\$ 714$ over the 1992-1998 period. We adjust all expenditures in the sample to 1998 dollars using the Consumer Price Index of Medical Services. Although the observed probability of prescription drug use is nearly constant with age, expenditures, if any, gradually fall (see Figure 1). Triangles represent the observed statistics from the actual sample; we discuss simulated observations indicated by circles later. This simple graph illustrates the complex relationship between medical care use and age. One might expect expenditures to rise with age as health is likely to be deteriorating. However, those individuals who survive to older ages may be healthier reflecting a negative relationship between medical care expenditures and age among survivors. That is, those individuals who live longer are likely to be in better health (relative to the health of those who died previously), and hence may spend less at older ages on prescription drugs.

Figure 2 illustrates similar patterns of Part A inpatient expenditures (conditional on any) with age (mean: $\$ 11,267)$. However, the probability of hospitalization increases dramatically with age from around $12 \%$ at age 65 to over $30 \%$ at ages above 90 . The lower average hospital expenses as individuals age suggest that the stays of older patients may be shorter than those of younger patients. This may be due to higher death rates or reflect the less aggressive treatment of those who are hospitalized at older ages. Figure 3 shows annual Part B physican expenditures by age. Nearly all Medicare-covered individuals have some Part B expenses within the year. On average, these expenditures are $\$ 1,588$.

Measurement of health status should reflect true health as accurately and broadly as possible. Rather than use subjective self-reported health, we select the somewhat more objective measures of functional status. (We estimated the model with both measures of health and found very few differences in the results.) In the MCBS, a survey of functional status is conducted between September and December in every calendar year. Half of the sample respondents report some functional limitation at some point during the survey period. About 15 percent express difficulties in Instrumental Activities of Daily Living (IADL) only, with more than 35 percent reporting difficulties in at least one Activity of Daily Living 
(ADL). The six categorical values of health are 1) no functional impairment; 2) any IADLs only; 3) 1 or 2 ADLs; 4) 3 or 4 ADLs; 5) 5 or 6 ADLs; and 6) death. Table 2 details one-year health transitions of the elderly over the sample period. This table highlights the extent of movement among health categories in general; obviously the transition rates differ by age and other characteristics. About $40 \%$ of the elderly remain in a given health state from one year to the next. However, transitions to poorer health are common. Death is more probable with increases in functional limitations with nearly $20 \%$ of those with 5-6 ADLs dying in a given year. Interestingly, the incidence of health improvement is significant. Almost $20 \%$ of the sample experiences improved health from one year to another.

Table 3 summarizes additional variables used to explain expenditures and health transitions. These include both endogenous variables (which are jointly modeled with the main expenditure and health equations) and exogenous variables. Note that most of the explanatory variables vary across time. The sources of major supplemental insurance for Medicare beneficiaries are the Medicare managed care option, Medicaid, employer-provided insurance, and individually-purchased insurance. In order to measure the effect of third-party coverage of drugs, we grouped employer-provided, privately-purchased, and managed care insurance by whether or not the plan offered outpatient prescription drug coverage. Thus, in the empirical model, supplemental insurance includes three dummy variables indicating whether the Medicare beneficiary has Medicaid, any private insurance with a drug benefit, or any private insurance without a drug benefit. (The supplemental health insurance decision, estimated jointly as an initial condition, is modeled as a 4-choice multinomial logit equation with no supplement to Medicare as the base outcome.) About $13 \%$ of the Medicare-covered sample respondents were also Medicaid beneficiaries, and $52 \%$ of the sample respondents were enrolled in at least one type of private insurance with a drug benefit. Altogether, almost two-thirds of the sample respondents had some type of outpatient prescription drug coverage.

Five diseases or injuries account for most health shocks among the elderly population. These include: cancer, heart disease, cerebrovascular diseases, respiratory system diseases, and hip and other body part fractures. In the empirical model, the health shocks, $S_{t}$, are measured by whether respondents were diagnosed in period $t$ with any one of these five life 
threatening diseases or injuries. On average over the seven-year span, diagnoses of cancer, heart disease, and respiratory system diseases (including pneumonia with heart/lung comorbidities, COPD, and influenza) were at rates of 9, 22, and 22 percent a year, respectively. Cerebrovascular disease and hip and other body part fractures were less frequent with these health shocks occurring at rates of 4 and 1 percent per year on average. The survey also includes self-reported chronic conditions present in any period. More than half of the sample respondents have or have had hypertension, 25 percent have had a heart attack, 34 percent have been diagnosed with cancer and 17 percent have diabetes. Case and Paxson (2004) find that differences in morbidity and mortality across genders can be explained by differences in the distribution of chronic conditions.

As a representative sample of aging Medicare beneficiaries, the average age of the sample is 75.2 years (see Table 3). Sixty percent of the sample are female. One-half of the respondents are married, and 40 percent are widowed. Minority populations account for 12 percent of the entire sample, and 27 percent of the sample live in a rural area.

\section{Results}

\subsection{Estimation Results}

The interpretation of results is difficult in this dynamic system of demand equations and health production with its feed-forward structure. First we discuss the signs and significance of the main explanatory variables in each equation, which qualitatively describes the shortrun effects. In section 5.2 we discuss simulation results to illustrate the influence of particular variables in the long run, taking into account changes in health status and mortality.

In our preferred model that controls for endogeneity (i.e., the jointly estimated set of correlated equations henceforth labeled with unobserved heterogeneity), drug coverage has no significant effect on whether a person purchases any prescription drugs (see Table 4a, second column), but does affect expenditures for those who purchase any (see Table $4 \mathrm{a}$, fourth column). The signs of the coefficients are generally in the expected direction, and depend on whether someone is disabled or has a chronic disease. For those who are

disabled, Medicaid and private drug coverage increase prescription drug expenditures in the short term. For those with chronic diseases, private insurance increases prescription drug 
expenditures. The only coefficient that has an unexpected sign is that of Medicaid's impact on conditional drug expenditures, which is negative. This implies that conditional on having at least one prescription, elderly persons on Medicaid spend less on prescription drugs than elderly with no coverage other than Medicare. This result may in part reflect that while Medicaid improves access to drugs among the elderly it does not necessarily encourage them to spend more on drugs.

Drug coverage has little influence on the probability or (log) level of hospital expenditures (see Table 4b, second and fourth columns). This is to be expected because all elderly persons have inpatient hospital care covered by Medicare. Prescription drug coverage should not have a direct effect on inpatient hospital care, other than as a substitute form of care. However drug coverage does affect expenditures on outpatient physician services (see Table 4c, second column). Those on Medicaid and with private insurance without drug coverage have higher physician expenditures in the short run.

To view the bias eliminated with our preferred approach, it is necessary to compare the coefficient estimates from our jointly estimated system of equations with those produced by estimating the equations independently (i.e., separate estimation of uncorrelated equations henceforth labeled without unobserved heterogeneity). The alternative approach treats previous behavior, health, and insurance as exogenous and hence does not account for correlation in individual unobservables across time or between contemporaneous endogenous variables. In models that do not control for unobserved heterogeneity, drug coverage appears to have a significant positive impact on the use of prescription drugs (see Table 4a, first column). Insurance also appears to play a greater role in influencing hospital and physician expenditures (see Tables $4 \mathrm{~b}$ and 4c). In particular, the coefficients on drug coverage are considerably larger when the endogeneity of insurance is not modeled. These findings are consistent with unobservable individual characteristics associated with adverse selection that generate an upward-biased correlation between health insurance coverage and utilization. When this adverse selection is modeled, the positive marginal effect of insurance coverage on expenditures is smaller. Hence, the first feature of our preferred model (endogenous insurance coverage) improves our understanding of the effect of coverage on utilization. Controlling for this unobserved heterogeneity reveals little change in the positive (in most cases) effect 
of drug coverage on prescription drug expenditure and inpatient expenditure, conditional on any expenditures.

In modeling the permanent and time-varying individual unobserved heterogeneity that is likely to influence insurance, expenditures, and health, we found three mass points to be sufficient to capture the distribution of permanent heterogeneity, and two mass points for time-varying heterogeneity. (Estimation with more mass points on either factor did not improve the fit of the model.) The estimated loadings are positive and jointly significant, suggesting that individuals with unobserved characteristics to the right of the distribution are more likely to use that health service and to spend more on it (see last two rows of Tables 4a through 4c). Therefore, expenditures are positively correlated both within a given period and across time. The results suggest that these outcomes are endogenous and correlated. Hence, feature two of our preferred model (joint estimation of different medical care services) is warranted; the model without heterogeneity does not allow for correlation in unobservables across contemporaneous outcomes. It should also be noted that the factor loadings on the unobserved heterogeneity in the insurance equation (Appendix Table A1) are also positive, suggesting that those in worse unobserved health, for example, are more likely to have supplemental coverage and have higher medical care expenditures. (Coefficients in the other initial condition equations are presented in Appendix Tables A2 and A3.)

We turn now to estimation results from the health production function. The importance of modeling this equation jointly with the expenditure equations is to capture correlation in the error terms associated with health outcomes and endogenous medical care inputs that affect health. Such correlation is confirmed if marginal effects of the endogenous inputs differ when heterogeneity is modeled and when it is not. While we observe only small differences, if any, in the coefficients explaining the relatively better health outcomes (in relationship to no health limitations), we find sizable differences in the estimates for the worst health outcomes. For example, the effects of medical care use on the probability of dying relative to having no functional limitations are much larger when unobserved heterogeneity is modeled. In particular, prescription drug expenditures have a non-linear negative marginal effect (note squared term) on the probability of dying, and that this effect is greater when we account for unobserved correlation between drug use and health outcomes. Notice also that 
while inpatient and physician services expenditures appear to reduce health (i.e., increase the probability of being in the worse health state), this effect is moderated for individuals with greater functional limitations. The sign of the heterogeneity factor loadings is consistent with the notion of unobserved bad health. The third feature of our preferred model (joint estimation of medical care inputs and health outcomes) appropriately relates health and medical care use over time.

Finally, we investigate the impact of lagged medical care use on current expenditures. Serial correlation in use as well as expenditures requires that permanent unobserved heterogeneity be modeled if we do not want to incorrectly assume that previous behavior causes current behavior. Differences in point estimates between a model with and without this heterogeneity demonstrate the importance of modeling the endogeneity of past use. In Table 4a, for example, we find that the effect of Part B expenditure in the previous year on the probability of any drug use in the current year switches signs from being positive and significant in the model that does not control for unobserved individual differences to negative and significant in the model with unobserved heterogeneity. Interestingly, Part B expenditures and hospitalization in the previous year both reduce drug expenditures in the current year. Drug use across years is positively related even after purging the estimates of bias associated with serial correlation. These estimates suggest that previous use has a direct effect on current use independent of its indirect effect through changes in health. In Table 4b, we again find that modeling the unobserved correlation between Part B expenditures and inpatient use changes the sign, with previous physician service use reducing probabilities of current hospitalization. Previous drug use does not affect hospitalization probabilities and expenditures when heterogeneity is modeled. The effects of expenditures in the previous year on Part B expenditures in the current year fall dramatically when we account for unobserved heterogeneity (Table 4c). Most importantly, we find that prescription drug use in the previous period reduces current physician service expenditures suggesting that drugs may be substitutes for physician care. We have attempted to adequately capture health with both the observed measures of health and the unobserved heterogeneity. If our efforts have been unsuccessful then lagged expenditures may, in part, reflect true health. We maintain, however, that our results confirm importance of the fourth feature of our preferred model 
(direct effects of lagged behavior). These findings will have significant effects on the long-run cost projections associated with a Medicare drug benefit. In section 5.2 we quantify these effects.

We demonstrate the fit of our preferred model by comparing observed outcomes of the sample with model predictions using estimated model parameters and observed explanatory variables. The top panel of Table 6 summarizes each outcome by year, as observed in the sample. The lower panel reports predictions from our model using the observed data as regressors. To demonstrate the fit of the model we use the observed values of covariates as they appear in the original data when generating predictions; we do not update behavior based on past predictions. We describe in Table 6 how well the model matches the unconditional distributions of expenditures and health. Comparisons of observed and predicted prescription drug use and expenditures, hospitalization rates and expenditures, and physician services expenditures by age are depicted in Figures 1, 2, and 3 (indicated by circles). The model fits these outcomes well, bearing in mind that the sample size gets relatively small at ages above 90 .

\subsection{Simulation of Drug Coverage}

The effect of drug coverage on health expenditures and health in this nonlinear dynamic model is best shown with simulations. The simulations quantify the long-run effect of drug coverage by incorporating the dynamic effects of behavior on future choices and health transitions. To answer the policy question of how expansion of prescription drug coverage to all elderly Medicare beneficiaries would affect health care expenditures, we choose a five-year period. This is long enough to demonstrate the importance of a dynamic model but not so

long as to simulate beyond our data. We simulate expenditures and health transitions of our sample over five years under three different drug coverage scenarios: no supplemental insurance beyond Medicare (i.e., no drug coverage), coverage by Medicaid, and coverage by private insurance with a drug benefit. We show results from models that do and do not control for unobserved heterogeneity.

The details of the simulation are straightforward. In each period we use the estimated model to predict demand for prescription drugs and Medicare Part A and B services for the 
entire sample of 14,439 individuals. We use these simulated input choices and the estimated health production function to update end-of-period health. This simulated health outcome is then transferred to the next period. Conditional on the updated health and previous (simulated) expenditures, expenditures are again simulated. This process can be repeated for any number of years. We use the simulated values of all endogenous right hand side variables but retain the observed (in the original data) values of exogenous variables (e.g., age, marital status, rural residency, etc.). Because we treat health shocks as exogenous, we simulate these events according to the observed distribution of health shocks in each year. Some people die each year; these observations are not replaced. We generate 400 simulations for each individual allowing for one draw from the permanent unobserved heterogeneity distribution for the five-year period and draws from the time-varying distribution every year. Predicted probabilities of any expenditures and health outcomes are mapped to the unit interval and a uniform random variable determines the outcome. Normal random errors are added to predicted log expenditures to determine expenditure outcomes. Simulations are repeated using the same random numbers but providing either a Medicaid insurance benefit or a private drug insurance benefit that influences drug consumption directly, and compared to simulations with no supplemental coverage.

Drug coverage increases prescription drug expenditures in our sample by 12.2 to 17.5 percent over a five-year period, according to our preferred model (see top half of Table 7). These comparisons are averaged over the entire sample, and simulate a policy change of going from no prescription drug coverage to either a typical Medicaid benefit or a typical private benefit. The model without heterogeneity suggests a larger average range of the increase from 10.6 to 20.3 percent (see bottom half of Table 7 ). In contrast to the substantial increase in drug expenditures, Part A and Part B expenditures increase only slightly over five years. On average, each individual spends 0.9 percent more on Part A expenditures and 2.5 percent more on Part B expenditures over five years if a Medicaid-like drug benefit is provided. The increasing rates for Part A and Part B expenditures are slightly higher if a drug benefit as generous as the private benefit is provided. The model without heterogeneity predicts that increases in these non-drug expenditures would be almost twice as large. Decreases in death rates associated with drug coverage are larger in the model with heterogeneity 
compared to the model without heterogeneity. The five-year survival rate increases from by 1.57 percentage points if a Medicaid-like drug benefit is provided. The increase in survival rate and disability rates among survivors are both higher if a drug benefit similar to private insurance is provided.

In an effort to further understand the effects of prescription drug coverage on health outcomes and health care expenditures, we categorize the health transitions of the simulated sample by changes in health outcomes over the five year period. That is, the health of survivors has either improved, remained the same, or deteriorated, or individuals may have died. The top panel of Table 8 details the composition of the sample when no drug benefit is available, and when benefits similar to Medicaid or private supplemental insurance are available. This decomposition reveals that a drug benefit reduces the five-year mortality rate by about 2 percentage points, but that the survivors are more likely to experience declines in their health rather than maintaining or improving their health. While this might be expected, it gives us an understanding of the associated increase in medical care expenditures. The bottom panel of Table 8 describes the medical care utilization within each category of health transition with different types of drug benefit. The largest percentage increases in prescription drug expenditures occurs among the survivors. Individuals who die before the end of the five-year period spent more on drugs when covered, but increased their consumption by at least one-third less than those who survived. This is particularly striking because survival is longer among those who died when some type of drug coverage is provided. The information on Part A and Part B expenditures reveals that individuals who die spend more on hospitalization and physician services despite contributing fewer years to the five-year total calculation. The behavior when drug coverage is introduced suggests that much of the increase in consumption occurs among those individuals who experience declines in health yet survive.

In Table 9 we glean more information on the expenditures and health outcomes of survivors. Here we define survivors as sole survivors or marginal survivors. Sole survivors are those individuals who live regardless of the drug benefit structure. Marginal survivors would have died if no drug benefit were available. Put differently, marginal survivors survive when either a Medicaid or private drug benefit is available. As expected, sole survivors are 
healthier in year one than marginal survivors. They are younger, more likely to be female, and have fewer functional limitations, with more than half of the sample $(57 \%)$ having no functional limitations. Although differences in age and health at baseline among these two groups explain some of the differences in health outcomes, we see that supplemental drug coverage results in very different medical care responses across the two groups. The sole survivors increase their drug consumption a moderate amount, but exhibit very little change in other expenditures. The marginal survivors, however, spend over 50\% more on drugs, and over $20 \%$ more on hospital and physician service expenditures.

Instead of updating the data each period to reflect the per-period simulated choices, we could use the model to predict behavior each year and retain the original values of explanatory variables in the following year. This calculation, which we refer to as the immediate effect, does not allow a policy change (such as the introduction of prescription drug benefits) to have dynamic effects. The calculated effects reflect static changes in behavior only. This simulation is consistent with results reported from static models that do not capture the effects of altered behavior on future outcomes. As with the five-year simulations, we compute the immediate effect both with and without unobserved heterogeneity.

Table 10 shows the immediate effect of drug coverage on the behavior of the elderly. The marginal effect of adding a Medicaid drug benefit is quite different when controlling for unobserved heterogeneity. The model without heterogeneity predicts a 7.5 percent increase in total drug expenditures if a Medicaid-like drug benefit is provided, while the prediction from our preferred model is lower (5.5 percent). The two models produce similar results when universal provision of a drug benefit resembles private coverage of prescription drugs. As expected, drug coverage has no influence on other medical care utilization during the same year when calculating the immediate effect. This is why it is beneficial to evaluate the long-run effect of this policy change. Drug coverage also influences end-of-period health. Most noticeably, the death probability is approximately 0.2 to 0.3 percentage points lower when drug coverage is provided universally than when it is not available. Admittedly, drug use appears to be positively related with worse health outcomes, conditional on survival. But this too, is expected. Prescription drug use might prevent death, but, in doing so, the proportion (of survivors) in worse health increases. 


\section{Discussion}

The simulation results suggest that a prescription drug benefit will increase the demand for prescription drugs (on average between 12.2 and 17.5 percent over 5 years), but that this increase will not be as large as that predicted by static models or those that do not account for the endogeneity of past decisions. Drug coverage will decrease the mortality rate of the elderly population, but will reflect increases in the average disability rate of the elderly population as more sick people are living longer. Over the long term, there is no obvious increase in demand for hospital care either among the survivors or among the entire population (including both survivors and decedents) in total. But we may expect a slight increase in demand for outpatient physician services. This effect, however, is smaller than would be predicted by using results from a static model and forecasting (which will not account for endogenous changes in health and past utilization), or failing to account for unobserved individual characteristics. Given the increase in survival rates and the increased use of other Medicare-covered services, Medicare's drug benefit will likely increase total Medicare costs. However, this additional burden reflects increased longevity (decreased mortality). For the healthier people, prescription drugs may help them maintain or improve their health conditions slightly, but for those who are in worse health and dying fast, a prescription drug benefit may help these people more significantly by reducing the mortality rate and extending longevity.

Our study contributes to the policy debate regarding the Medicare prescription drug benefit in several ways. First, our study goes beyond looking at the effect of drug policy on the demand for drugs only, and investigates the possible dynamic effects of this policy change on Medicare beneficiaries' health and other Medicare-covered services expenditures. Second, our study provides evidence that health care behavior of the elderly is correlated over time, and that the significance of this relationship is dependent on unobserved permanent heterogeneity as well as time-varying unobserved heterogeneity. Third, our study produces

both short-term and long-run predictions of the effects of a Medicare prescription drug benefit that illustrate the dynamic effects of this policy change on total Medicare costs as well as the health status of Medicare beneficiaries in our sample. Our results indicate that without consideration of the dynamic effects of the new Medicare Drug Bill, the real cost of this 
policy change to Medicare could be even higher than current estimates due to the increase in survival and the increased demand for other Medicare-covered services. With a higher percentage of older people surviving with ADLs, health policy makers should consider all consequences of this policy change. For example, the drug benefit may lead, indirectly, to a higher demand for long-term care or increased reliance on state Medicaid programs. Further research into these additional indirect effects is warranted. 


\section{References}

Adams, A.S., Soumerai, S.B. and Ross-Degnan, D. "The Case for a Medicare Drug Coverage Benefit: A Critical Review of the Empirical Evidence." Annual Review of Public Health, 2001a, (22), pp. 49-61.

_ "Utilization of Antihypertensive Drugs among Medicare Enrollees." Health Affairs, 2001b.

Adler, G. "A Profile of the Medicare Current Beneficiary Survey." Health Care Financing Review, 1994, 15(4), pp. 153-63.

Angeles, G., Guilkey, D., and Mroz, T. "Purposive Program Placement and the Estimation of Family Planning Program Effects in Tanzania." Journal of the American Statistical Association, 1998, 93(443): 884-899.

Arellano, M. and Bond S. "Some Tests of Specification for Panel Data: Monte Carlo Evidence and an Application to Employment Equations." Review of Economic Studies, 1991, 58, pp. $277-297$.

Bhargava, A. and Sargan, J.D. "Estimating Dynamic Random Effects Models From Panel Data Covering Short Time Periods." Econometrica, 1983, 51(6), pp. 1635-1659.

Blau, D. and Gilleskie, D. "Retiree Health Insurance and Labor Force Behavior of Older Men in the 1990's." Review of Economics and Statistics, 2001, 83(1), pp. 60-84.

Blau, D. and Hagy, A. "The Demand for Quality in Child Care." Journal of Political Economy, 1998, 106(1): 104-146.

Blustein, J. "Drug Coverage and Drug Purchases by Medicare Beneficiaries with Hypertension." Health Affairs, 2000, 19, pp. 219-30.

Case, A. and Paxson, C. "Sex Differences in Morbidity and Mortality." Working paper, 2004.

Cutler, D. "The Incidence of Adverse Medical Outcomes under Prospective Payment." Econometrica, 1995, 63(1): 29-50. 
Cutler, D. "Declining Disability among the Elderly." Health Affairs, 2001, 20(6), pp. 11-28.

Department of Health and Human Services. A Profile of Medicare: Chart Book, 1998, Rockville, MD.

Federman, A.D., Alyce, S.A., Ross-Degnan, D., Sourmerai, S.B. and Ayanina, J.Z. "Supplemental Insurance and Use of Effective Cardiovascular Drugs among Elderly Medicare Beneficiaries with Coronary Heart Disease." JAMA, 2001, 286(14), pp. 1732-39.

Ferrucci, L. and Guralnik, J. "Hospital Diagnoses, Medicare Charges, and Nursing Home Admissions in the Year When Older Persons Become Severely Disabled." JAMA, 1997, 277, pp. $728-34$.

Fillenbaum, G.G., Hanlon, J.T., Corder, E.H., Ziqubu-Page, T., Wall, W.E. and Brock, D. "Prescription and Nonprescription Drug Use among Black and White Community-Residing Elderly." American Journal of Public Health, 1993, 83, pp. 1577-1582.

Goldman, D. "Managed Care as a Public Cost Containment Mechanism." RAND Journal of Economics, 1995 , 26(2), pp. 277-295.

Gowrisankaran, G. and Town R.J. "Managed Care, Drug Benefit and Mortality: An Analysis of the Elderly." NBER Working Paper No. 10204.

Grossman, M. "On the Concept of Health Capital and the Demand for Health." Journal of Political Economy, 1972, 80(2): pp. 223-255.

Heckman, J. and Singer, B. "A Method for Minimizing the Impact of Distributional Assumptions in Econometric Models for Duration Data." Econometrica, 1983, 52, pp. 271-320.

Hoynes, H. "Welfare Transfers in Two-parent Families: Labor Supply and Welfare Participation under AFDC-UP." Econometrica, 1996, 64(2): 295-332.

$\mathrm{Hu}$, W. "Child Support, Welfare Dependency, and Women's Labor Supply." Journal of Human Resources, 1999, 34(1): 71-103.

Johnson, R.E., Goodman, M.J., Hornbook, M.C. and Eldredge, M.B. "The Impact of Increasing Patient Prescription Drug Cost-Sharing on Therapeutic Classes of Drugs Received and on the Health Status of Elderly HMO Members." Health Services Research, 1997, 32, pp. 103-22. 
Kreider, B. and Riphahn, R. "Explaining Applications to the US Disability System - A Semiparametric Approach." Journal of Human Resources, 2000, 35(1): 82-115.

"The Impact of New Drug Launches on Longevity: Evidence from Longitudinal Disease-Level Data from 52 Countries, 1982-2001." NBER Working Paper, 2003, No. W9754.

Lillard, L.A., Rogowski, J. and Kington, R. "Insurance Coverage for Prescription Drugs: Effects on Use and Expenditures in the Medicare Population." Medical Care, 1999, 37, pp. 926-36.

Long, S.H. "Prescription Drugs and the Elderly: Issues and Options." Health Affairs, 1994, 13, pp. 157-74.

Mays, G. and Norton, E.C. "Managed Care Contracting and Medical Care for the Uninsured: Untangling Selection from Production." Health Services and Outcomes Research Methodology, 2000, 1(3-4), pp. 305-334.

Mello, M., Stearns, S., and Norton, E.C. "Do Medicare HMOs Still Reduce Health Services Use after Controlling for Selection Bias?" Health Economics, 2002, 11, pp. 323-340.

Mroz, T.A. "Discrete Factor Approximation in Simultaneous Equation Models: Estimating the Impact of a Dummy Endogenous Variable on a Continuous Outcome." Journal of Econometrics, 1999, 92, pp. 233-74.

Philipson, T.J. and Becker, G.S. "Old-Age Longevity and Mortality-Contingent Claims." Journal of Political Economy, 1998 106(3), pp. 551-573.

Poisal, J.A. and Murray, L. "Growing Differences between Medicare Beneficiaries with and without Drug Coverage." Health Affairs, 2001, 20(2), pp. 75-85.

Poisal, J.A., Murray, L.A., Chulis, G.S. and Cooper, B.S. "Prescription Drug Coverage and Spending for Medicare Beneficiaries." Health Care Financing Review, 1999, 20(3), pp. 15-25.

Reeder, C.E. and Nelson, A.A. "The Differential Impact of Copayment on Drug Use in a Medicaid Population." Inquiry, 1985, 22, pp. 396-403.

Rogowski, J., Lillard, L.A. and Kington, R. "The Financial Burdens of Prescription Drug Use among Elderly Persons." Gerontologist, 1997, 37, pp. 475-82. 
Soumerai, S.B., Avorn, J., Ross-Degan, D. and Fortmaker, S. "Payment Restrictions for Prescription Drugs under Medicaid: Effect on Therapy, Cost, and Equity." New England Journal of Medicine, 1987, 317, pp. 550-56.

Soumerai, S.B., McLaughlin, T.J., Ross-Degnan, D., Casteris, C.S. and Bollini, P. "Effects of Limiting Medicaid Drug-Reimbursement Benefits on the Use of Psychotropic Agents and Acute Mental Health Services by Patients with Schizophrenia." New England Journal of Medicine, 1994, 331(650-655).

Soumerai, S.B. and Ross-Degnan, D. "Experience of State Drug Benefit Program." Health Affairs, 1990, 9, pp. 36-54.

. "Inadequate Prescription Drug Coverage for Medicare Enrollees-a Call to Action." New England Journal of Medicine, 1999, 340(9), pp. 722-28.

Soumerai, S.B., Ross-Degnan, D., Avorn, J., McLaughlin, T.J. and Choodnovskiy, I. "Effects of Medicaid Drug-Payment Limits on Admission to Hospitals and Nursing Homes." New England Journal of Medicine, 1991, 325(1072-1077).

Stearns, S.C., Norton, E.C. and Yang, Z. "Disability Offsets in the Expenditure Trade-Off between Age and Proximity to Death." Working paper, 2003.

Steinman, M.A., Sands, L.P. and Covinsky, K.E. "Self-Restriction of Medications Due to Cost in Seniors without Prescription Coverage: A National Survey." Journal of General Internal Medicine, 2001, 16, pp. 793-99.

Stuart, B. and Coulson, N.E. "Dynamic Aspects of Prescription Drugs Use in an Elderly Population." Health Services Research, 1993, 28, pp. 237-64.

. "Use of Outpatient Drugs as Death Approaches." Health Care Finance Review, 1994, 15 , pp. $63-82$.

Stuart, B. and Grana, J. "Are Prescribed and over-the-Counter Medicines Economic Substitutes? A Study of the Effects of Health Insurance on Medicine Choices by the Elderly." Medical Care, 1995, 33, pp. 487-501. 
Tamblyn, R., Laprise, R., Hanley, J.A., Abrahamowicz, M., Scott, S., Mayor, N., Hurley, J., Grad, R., Latimer, E., Perreault, R., et al. "Adverse Events Associated with Prescription Drug Cost-Sharing among Poor and Elderly Persons." JAMA, 2001, 285(4), pp. 421-29. 


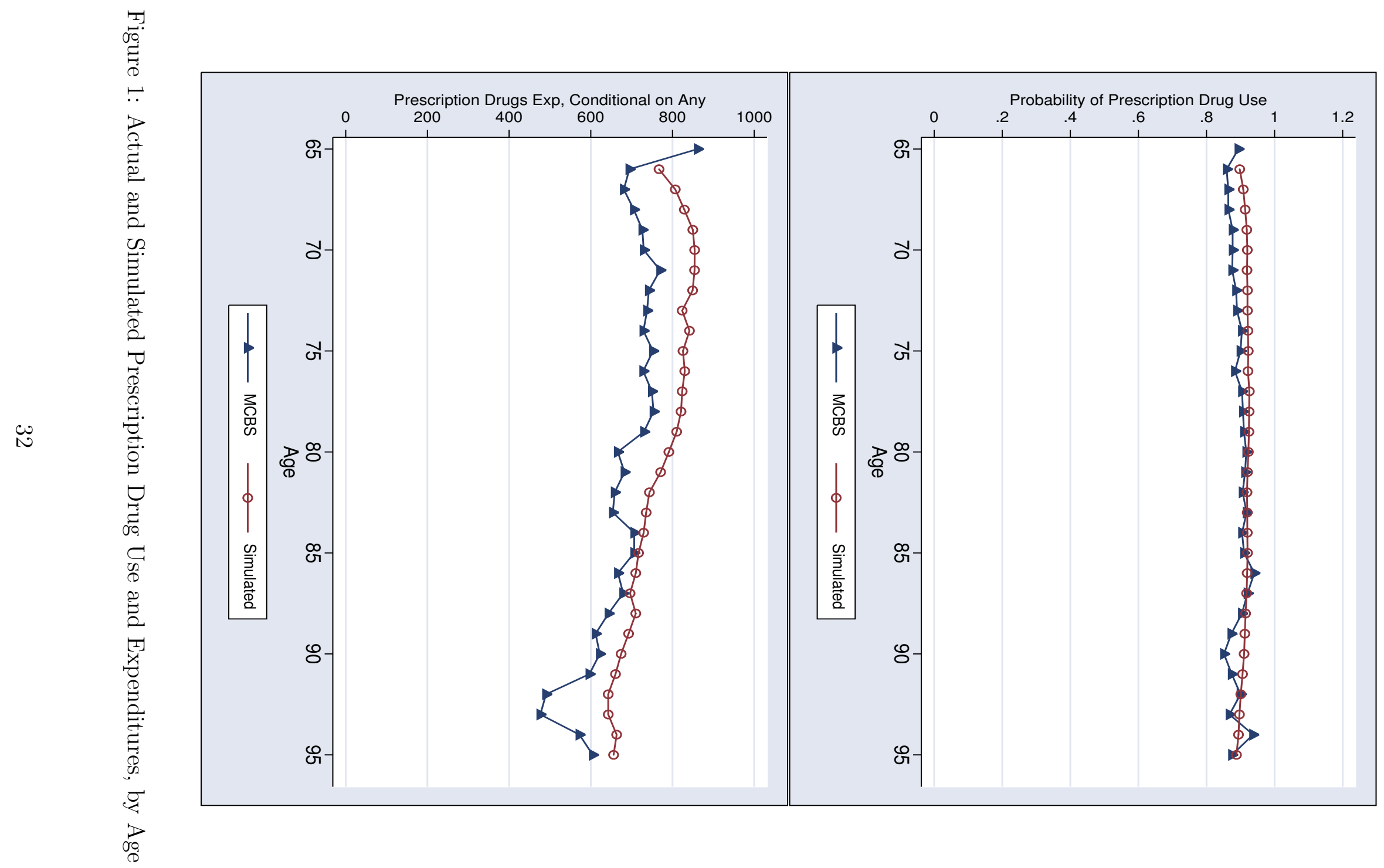




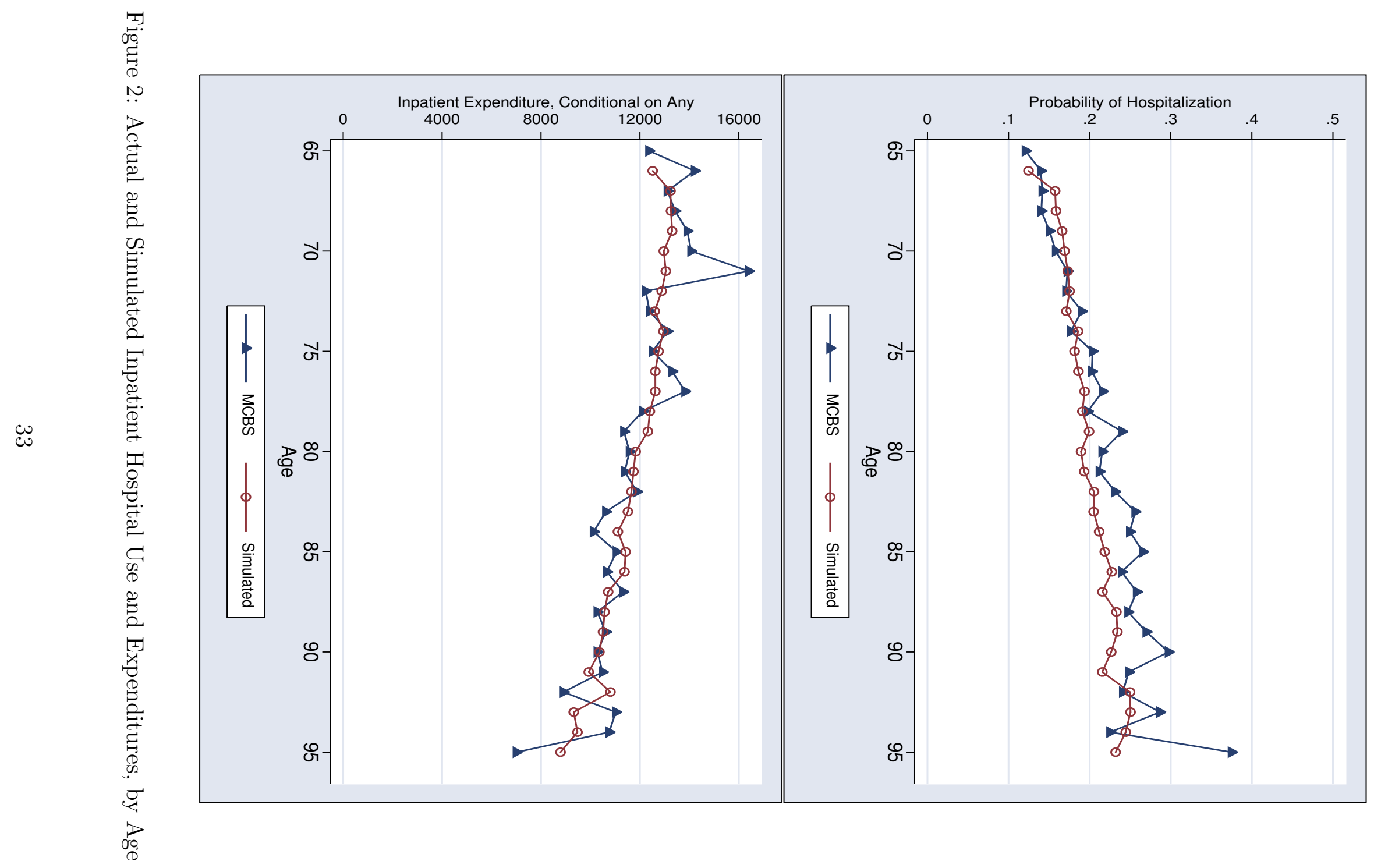




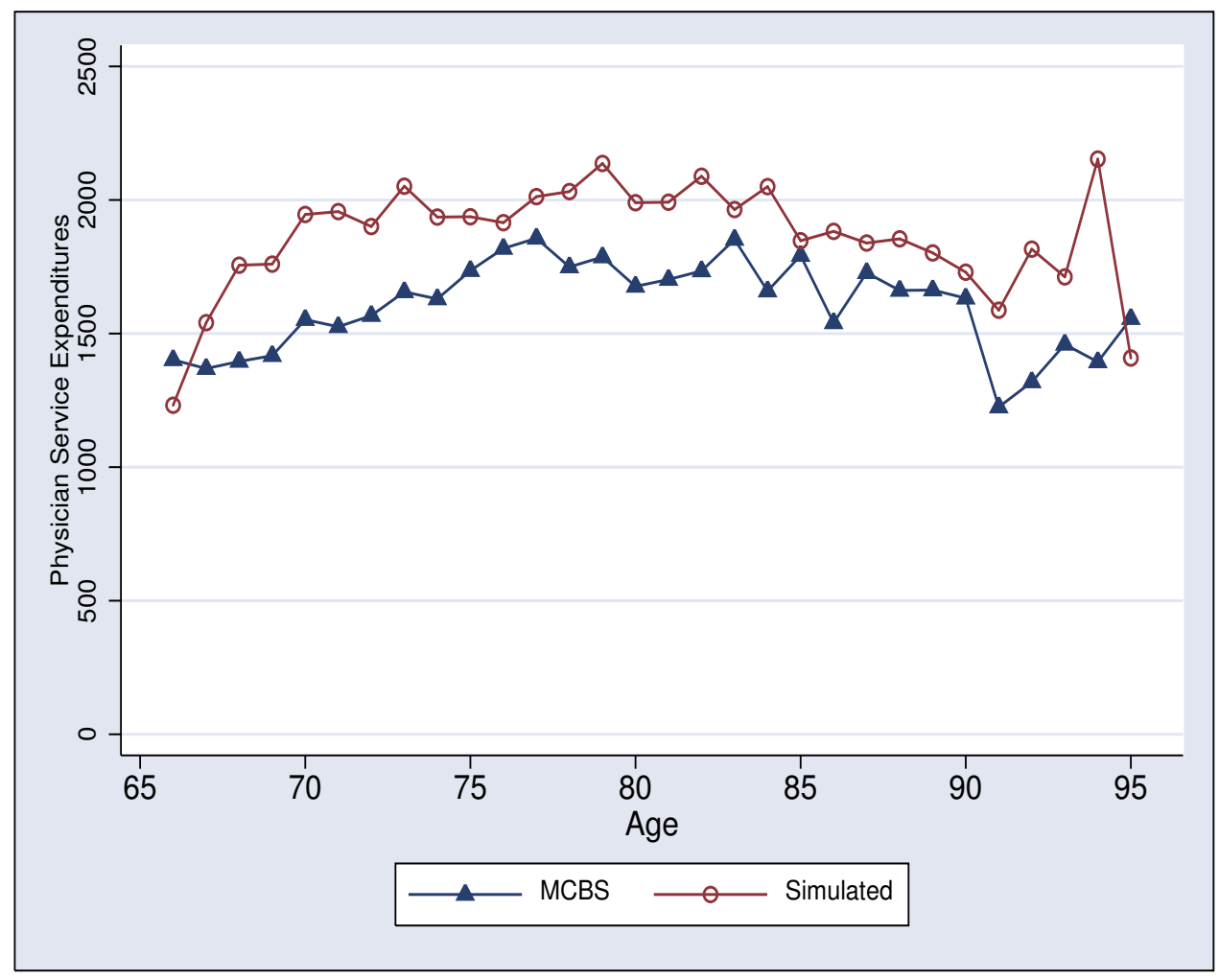

Figure 3: Actual and Simulated Physician Service Expenditures, by Age 
Table 1: Empirical Distribution of Participation in MCBS, 1992-1998

\begin{tabular}{|c|c|c|}
\hline Years Followed & $\begin{array}{c}\# \\
\text { of inds }\end{array}$ & $\begin{array}{c}\% \\
\text { of sample }\end{array}$ \\
\hline At Least 2 Years & 14,439 & 100 \\
\hline At Least 3 Years & 9,999 & 69 \\
\hline At Least 4 Years & 2,570 & 18 \\
\hline More than 4 Years & 727 & 5 \\
\hline Exactly 2 Years & 4,440 & 31 \\
\hline Exactly 3 Years & 7,429 & 51 \\
\hline Exactly 4 Years & 1,843 & 13 \\
\hline More than 4 Years & 727 & 5 \\
\hline 1992 & 5,574 & 13 \\
\hline 1993 & 6,692 & 16 \\
\hline 1994 & 6,804 & 16 \\
\hline 1995 & 6,136 & 15 \\
\hline 1996 & 6,123 & 15 \\
\hline 1997 & 6,488 & 15 \\
\hline 1998 & 4,357 & 10 \\
\hline \multirow{2}{*}{\multicolumn{2}{|c|}{$\begin{array}{l}\text { Number of unique individuals } \\
\text { Number of person-year observations }\end{array}$}} & 14,439 \\
\hline & & 42,174 \\
\hline
\end{tabular}


Table 2: Observed One-Year Health Status Transitions

\begin{tabular}{|c|c|c|c|c|c|c|c|}
\hline & \multirow[b]{2}{*}{$\%$} & \multicolumn{6}{|c|}{$\underline{\text { Health Status }}_{t+1}$} \\
\hline & & $\begin{array}{c}\text { No } \\
\mathrm{I} / \mathrm{ADLs}\end{array}$ & $\begin{array}{c}\text { IADLs } \\
\text { only }\end{array}$ & $\begin{array}{c}1-2 \\
\text { ADLs }\end{array}$ & $\begin{array}{c}3-4 \\
\text { ADLs }\end{array}$ & $\begin{array}{c}5-6 \\
\text { ADLs }\end{array}$ & Die \\
\hline \multicolumn{8}{|c|}{ Health Status $_{t}$} \\
\hline No I/ADLs & 0.50 & 0.79 & 0.10 & 0.08 & 0.01 & 0.01 & 0.02 \\
\hline IADLs only & 0.15 & 0.29 & 0.38 & 0.23 & 0.04 & 0.01 & 0.05 \\
\hline 1-2 ADLs & 0.20 & 0.18 & 0.15 & 0.45 & 0.11 & 0.04 & 0.07 \\
\hline 3-4 ADLs & 0.07 & 0.03 & 0.06 & 0.30 & 0.35 & 0.17 & 0.10 \\
\hline 5-6 ADLs & 0.03 & 0.01 & 0.20 & 0.08 & 0.19 & 0.50 & 0.20 \\
\hline Dead & 0.05 & 0.00 & 0.00 & 0.00 & 0.00 & 0.00 & 1.00 \\
\hline
\end{tabular}


Table 3: Description of Additional Explanatory Variables

\begin{tabular}{|c|c|c|}
\hline Variable & Mean & Std Dev \\
\hline \multicolumn{3}{|l|}{ Supplemental Insurance (omitted: none) } \\
\hline Medicaid & 0.13 & 0.32 \\
\hline Private Insurance with Drug Benefits & 0.52 & 0.50 \\
\hline Private Insurance without Drug Benefits & 0.27 & 0.44 \\
\hline \multicolumn{3}{|l|}{ Health Shocks (new diagnosis in $t$ ) } \\
\hline Cancer (ICD-9 140-209) & 0.09 & 0.23 \\
\hline Heart Diseases (ICD-9 390-430) & 0.22 & 0.41 \\
\hline Cerebrovascular Diseases (ICD-9 430-439) & 0.04 & 0.19 \\
\hline Respiratory System Diseases (ICD-9 480-496) & 0.22 & 0.41 \\
\hline Hip and Other Fracture (ICD-9 820-830) & 0.01 & 0.11 \\
\hline \multicolumn{3}{|l|}{ Self-Reported Chronic Conditions } \\
\hline Cancer & 0.34 & 0.47 \\
\hline Diabetes & 0.17 & 0.37 \\
\hline Emphysema, Asthma, COPD & 0.14 & 0.35 \\
\hline Hardening of Arteries & 0.15 & 0.36 \\
\hline Heart Attack & 0.25 & 0.43 \\
\hline Hypertension & 0.57 & 0.50 \\
\hline Other Heart Diseases & 0.31 & 0.46 \\
\hline Stroke & 0.12 & 0.32 \\
\hline Age (range: 65-104 years) & 75.26 & 7.17 \\
\hline Education (range: 0-18 years) & 10.13 & 4.22 \\
\hline Male (omitted: female) & 0.41 & 0.49 \\
\hline Rural Resident (omitted: urban) & 0.27 & 0.44 \\
\hline \multicolumn{3}{|l|}{ Race (omitted: white) } \\
\hline Black & 0.09 & 0.29 \\
\hline Asian & 0.01 & 0.07 \\
\hline Other Non-White & 0.02 & 0.15 \\
\hline \multicolumn{3}{|l|}{ Marital Status (omitted: married) } \\
\hline Widowed & 0.38 & 0.49 \\
\hline Divorced or Separated & 0.10 & 0.30 \\
\hline
\end{tabular}

Note: Other explanatory variables include lagged medical care use, health status, year indicators, and polynomials and interactions. 


\begin{tabular}{|c|c|c|c|c|c|c|c|c|}
\hline \multirow[b]{3}{*}{ Supplemental Insurance } & \multicolumn{4}{|c|}{ Any Expenditure } & \multicolumn{4}{|c|}{$\ln ($ Expenditure $\mid$ Any $)$} \\
\hline & \multicolumn{2}{|c|}{$\begin{array}{l}\text { Without Unobs'd } \\
\text { Heterogeneity }\end{array}$} & \multicolumn{2}{|c|}{$\begin{array}{l}\text { With Unobs'd } \\
\text { Heterogeneity }\end{array}$} & \multicolumn{2}{|c|}{$\begin{array}{l}\text { Without Unobs'd } \\
\text { Heterogeneity }\end{array}$} & \multicolumn{2}{|c|}{$\begin{array}{l}\text { With Unobs'd } \\
\text { Heterogeneity }\end{array}$} \\
\hline & & & & & & & . & \\
\hline Medicaid & $\begin{array}{c}0.288 \\
(0.149)\end{array}$ & $*$ & $\begin{array}{c}0.181 \\
(0.158)\end{array}$ & & $\begin{array}{l}-0.058 \\
(0.042)\end{array}$ & & $\begin{array}{l}-0.081 \\
(0.042)\end{array}$ & $*$ \\
\hline Private Insurance with Drug Coverage & $\begin{array}{c}0.210 \\
(0.099)\end{array}$ & $* *$ & $\begin{array}{c}0.154 \\
(0.105)\end{array}$ & & $\begin{array}{c}0.074 \\
(0.029)\end{array}$ & $* *$ & $\begin{array}{c}0.072 \\
(0.029)\end{array}$ & $* *$ \\
\hline Private Insurance without Drug Coverage & $\begin{array}{c}0.163 \\
(0.090)\end{array}$ & * & $\begin{array}{l}-0.015 \\
(0.095)\end{array}$ & & $\begin{array}{l}-0.035 \\
(0.024)\end{array}$ & & $\begin{array}{l}-0.057 \\
(0.025)\end{array}$ & $* *$ \\
\hline Medicaid $\times$ Disabled & $\begin{array}{c}0.125 \\
(0.167)\end{array}$ & & $\begin{array}{c}0.098 \\
(0.176)\end{array}$ & & $\begin{array}{c}0.095 \\
(0.037)\end{array}$ & $* *$ & $\begin{array}{c}0.099 \\
(0.038)\end{array}$ & $* *$ \\
\hline Medicaid $\times$ Chronic Disease & $\begin{array}{l}-0.054 \\
(0.187)\end{array}$ & & $\begin{array}{l}-0.080 \\
(0.194)\end{array}$ & & $\begin{array}{c}0.116 \\
(0.038)\end{array}$ & $* *$ & $\begin{array}{c}0.116 \\
(0.038)\end{array}$ & $* *$ \\
\hline Private Drug Benefit $\times$ Chronic Disease & $\begin{array}{l}-0.002 \\
(0.119)\end{array}$ & & $\begin{array}{l}-0.021 \\
(0.115)\end{array}$ & & $\begin{array}{l}-0.023 \\
(0.026)\end{array}$ & & $\begin{array}{l}-0.027 \\
(0.026)\end{array}$ & \\
\hline \multicolumn{9}{|l|}{ Lagged Health Care Utilization } \\
\hline Prescription Drug Expenditure in the Previous Year & $\begin{array}{c}0.671 \\
(0.013)\end{array}$ & $* *$ & $\begin{array}{c}0.684 \\
(0.011)\end{array}$ & $* *$ & $\begin{array}{c}0.483 \\
(0.003)\end{array}$ & $* *$ & $\begin{array}{c}0.484 \\
(0.003)\end{array}$ & $* *$ \\
\hline Hospitalized in Previous Year & $\begin{array}{l}-0.174 \\
(0.117)\end{array}$ & & $\begin{array}{l}-0.001 \\
(0.121)\end{array}$ & & $\begin{array}{l}-0.010 \\
(0.019)\end{array}$ & & $\begin{array}{c}0.018 \\
(0.018)\end{array}$ & \\
\hline Hospitalized in 4th Quarter of Previous Year & $\begin{array}{l}-0.892 \\
(0.162)\end{array}$ & $* *$ & $\begin{array}{l}-1.005 \\
(0.167)\end{array}$ & $* *$ & $\begin{array}{l}-0.032 \\
(0.029)\end{array}$ & & $\begin{array}{l}-0.041 \\
(0.029)\end{array}$ & \\
\hline Physician Service Expenditure in the Previous Year & $\begin{array}{c}0.047 \\
(0.010)\end{array}$ & $* *$ & $\begin{array}{c}-0.059 \\
(0.013)\end{array}$ & $* *$ & $\begin{array}{c}0.011 \\
(0.002)\end{array}$ & $* *$ & $\begin{array}{l}-0.006 \\
(0.003)\end{array}$ & $* *$ \\
\hline Unobserved Heterogeneity & & & & & & & . & \\
\hline Factor loading on permanent heterogeneity, $\rho$ & - & & $\begin{array}{c}0.205 \\
(0.096)\end{array}$ & $* *$ & - & & $\begin{array}{c}0.010 \\
(0.024)\end{array}$ & \\
\hline Factor loading on time-varying heterogeneity, $\omega$ & - & & $\begin{array}{c}1.505 \\
(0.065)\end{array}$ & $* *$ & - & & $\begin{array}{c}0.349 \\
(0.019)\end{array}$ & $* *$ \\
\hline
\end{tabular}

Note: Standard errors are in parentheses. ${ }^{* *}$ indicates joint significance at the $5 \%$ level; ${ }^{*} 10 \%$ level.

Disabled indicator defined as any IADL or ADL (50\% of sample). Chronic Disease indicator defined as any chronic disease reported on or before current period ( $33 \%$ of sample). Additional explanatory variables include those in Table 3 .

See bottom of Table 4c for description of heterogeneity distributions. 
Table 4b: Selected Parameter Estimates Explaining Inpatient Hospital Expenditures (Part A)

\begin{tabular}{|c|c|c|c|c|c|c|c|c|}
\hline \multirow{3}{*}{ Supplemental Insurance } & \multicolumn{4}{|c|}{ Any Expenditure } & \multicolumn{4}{|c|}{$\ln ($ Expenditure | Any) } \\
\hline & \multicolumn{2}{|c|}{$\begin{array}{l}\text { Without Unobs'd } \\
\text { Heterogeneity }\end{array}$} & \multicolumn{2}{|c|}{$\begin{array}{l}\text { With Unobs'd } \\
\text { Heterogeneity }\end{array}$} & \multicolumn{2}{|c|}{$\begin{array}{l}\text { Without Unobs'd } \\
\text { Heterogeneity }\end{array}$} & \multicolumn{2}{|c|}{$\begin{array}{l}\text { With Unobs'd } \\
\text { Heterogeneity }\end{array}$} \\
\hline & & & & & & & & \\
\hline Medicaid & $\begin{array}{c}0.089 \\
(0.083)\end{array}$ & & $\begin{array}{c}0.043 \\
(0.088)\end{array}$ & & $\begin{array}{l}-0.013 \\
(0.065)\end{array}$ & & $\begin{array}{l}-0.009 \\
(0.063)\end{array}$ & \\
\hline Private Insurance with Drug Coverage & $\begin{array}{l}0.174 \\
(0.074)\end{array}$ & ** & $\begin{array}{l}0.158 \\
(0.079)\end{array}$ & $* *$ & $\begin{array}{l}-0.063 \\
(0.060)\end{array}$ & & $\begin{array}{l}-0.023 \\
(0.058)\end{array}$ & \\
\hline Private Insurance without Drug Coverage & $\begin{array}{l}0.175 \\
(0.077)\end{array}$ & $* *$ & $\begin{array}{l}0.118 \\
(0.081)\end{array}$ & & $\begin{array}{l}0.020 \\
(0.061)\end{array}$ & & $\begin{array}{c}0.026 \\
(0.060)\end{array}$ & \\
\hline \multicolumn{9}{|l|}{ Lagged Health Care Utilization } \\
\hline Prescription Drug Expenditure in the Previous Year & $\begin{array}{c}0.023 \\
(0.011)\end{array}$ & $* *$ & $\begin{array}{c}0.012 \\
(0.011)\end{array}$ & & $\begin{array}{l}-0.015 \\
(0.008)\end{array}$ & * & $\begin{array}{c}-0.009 \\
(0.008)\end{array}$ & \\
\hline Hospitalized in the Previous Year & $\begin{array}{c}0.660 \\
(0.046)\end{array}$ & ** & $\begin{array}{c}0.733 \\
(0.051)\end{array}$ & $* *$ & $\begin{array}{l}0.050 \\
(0.033)\end{array}$ & & $\begin{array}{c}0.085 \\
(0.033)\end{array}$ & $* *$ \\
\hline Physician Service Expenditure in the Previous Year & $\begin{array}{l}0.004 \\
(0.009)\end{array}$ & & $\begin{array}{l}-0.046 \\
(0.010)\end{array}$ & ** & $\begin{array}{l}0.050 \\
(0.007)\end{array}$ & $* *$ & $\begin{array}{l}0.026 \\
(0.007)\end{array}$ & $* *$ \\
\hline \multicolumn{9}{|l|}{ Unobserved Heterogeneity } \\
\hline Factor loading on permanent heterogeneity, $\rho$ & - & & $\begin{array}{c}0.065 \\
(0.078)\end{array}$ & & - & & $\begin{array}{c}0.021 \\
(0.062)\end{array}$ & \\
\hline Factor loading on time-varying heterogeneity, $\omega$ & - & & $\begin{array}{l}1.390 \\
(0.067)\end{array}$ & ** & - & & $\begin{array}{c}0.949 \\
(0.105)\end{array}$ & $* *$ \\
\hline
\end{tabular}

Note: Standard errors are in parentheses. ${ }^{* *}$ indicates joint significance at the $5 \%$ level; ${ }^{*} 10 \%$ level. Additional explanatory variables include those in Table 3 . See bottom of Table $4 \mathrm{c}$ for description of heterogeneity distributions. 
Table 4c: Selected Parameter Estimates Explaining Physician Service Expenditures (Part B)

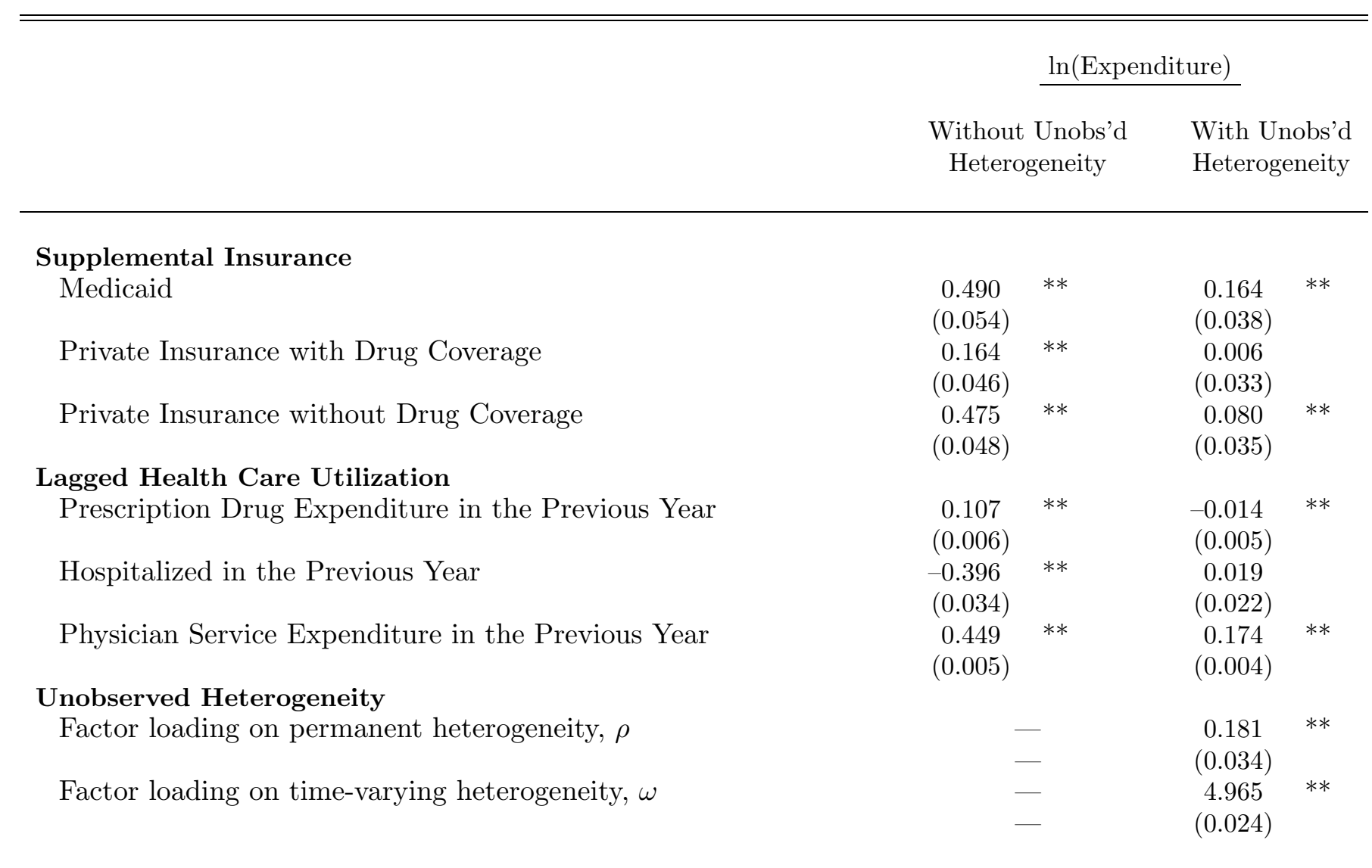

Note: Standard errors are in parentheses. ${ }^{* *}$ indicates joint significance at the $5 \%$ level; ${ }^{*} 10 \%$ level.

Additional explanatory variables include those in Table 3. The discrete mass points of the permanent

heterogeneity occur at $0.0,0.69$, and 1.0 with estimated probabilities of $0.16,0.27$, and 0.55 , respectively.

The distribution of time-varying heterogeneity has mass at 0.0 and 1.0 with estimated weights

of 0.16 and 0.83 . 
Table 5: Selected Parameter Estimates Explaining End-of-Period Health Status Transitions (relative to the outcome no functional status limitations)

Outcome: Die

Without Unobs'd

With Unobs'd

Heterogeneity

Heterogeneity

Health Care Utilization during period

Prescription Drug Expenditure

$\begin{array}{ccccc}0.088 & & 0.092 & \\ (0.061) & & (0.067) & \\ -0.064 & * * & -0.067 & * * \\ (0.008) & & (0.009) & \\ 0.361 & * * & 0.356 & * * \\ (0.021) & & (0.023) & \\ 0.042 & & 0.136 & * * \\ (0.035) & & (0.067) & \\ & & & \\ 1.727 & * * & 1.687 & * * \\ (0.289) & & (0.297) & \\ 2.369 & * * & 2.299 & * * \\ (0.260) & & (0.267) & \\ 5.601 & * * & 5.606 & * * \\ (0.617) & & (0.576) & \\ 6.442 & * * & 6.265 & * * \\ (0.881) & & (0.673) & \end{array}$

Interaction of Health Status and Utilization

IADLs only $\times$ Prescription Drug Expenditure

1-2 ADLs $\times$ Prescription Drug Expenditure

$0.036 \quad 0.039$

$(0.049) \quad(0.052)$

$0.042 \quad 0.053$

$(0.045) \quad(0.047)$

3-4 ADLs $\times$ Prescription Drug Expenditure

0.114

0.125

$(0.096)$

$(0.094)$

5-6 ADLs $\times$ Prescription Drug Expenditure

0.123

0.134

$(0.152)$

$(0.144)$

IADLs only $\times$ Inpatient Expenditure

0.007

0.002

$(0.027) \quad(0.044)$

1-2 ADLs $\times$ Inpatient Expenditure

$0.044 * \quad 0.044$

$(0.025) \quad(0.026)$

3-4 ADLs $\times$ Inpatient Expenditure

0.007

0.006

$(0.050)$

$(0.049)$

5-6 ADLs $\times$ Inpatient Expenditure

$-0.173$

$-0.179$

$(0.082)$

$(0.083)$

IADLs only $\times$ Physician Service Expenditure

$-0.036$

$-0.031$

$(0.046)$

$-0.084$

$(0.042)$

$-0.296$

$(0.089)$

$(0.049)$

1-2 ADLs $\times$ Physician Service Expenditure

3-4 ADLs $\times$ Physician Service Expenditure

5-6 ADLs $\times$ Physician Service Expenditure

$-0.054$

$-0.084$

$(0.043)$

$-0.308 \quad * *$

$(0.131)$

$(0.093)$

$-0.039$

Factor loading on permanent heterogeneity, $\rho$

$-$

$(0.125)$

$0.454 * *$

Factor loading on time-varying heterogeneity, $\omega$

$(0.148)$

$-0.913 \quad * *$

$(0.180)$

Note: Standard errors are in parentheses. ${ }^{* *}$ indicates joint significance at the $5 \%$ level; ${ }^{*} 10 \%$ level Additional explanatory variables include individual demographic information. 
Without Unobs'd Heterogeneity
With Unobs'd

Heterogeneity

Health Care Utilization during period

Prescription Drug Expenditure

Square of Prescription Drug Expenditure

Inpatient Care Expenditure

Physician Service Expenditure

Health Status at beginning of period

IADLs only

1-2 ADLs

3-4 ADLs

5-6 ADLs

Interaction of Health Status and Utilization

IADLs only $\times$ Prescription Drug Expenditure

1-2 ADLs $\times$ Prescription Drug Expenditure

3-4 ADLs $\times$ Prescription Drug Expenditure

5-6 ADLs $\times$ Prescription Drug Expenditure

IADLs only $\times$ Inpatient Expenditure

1-2 ADLs $\times$ Inpatient Expenditure

3-4 ADLs $\times$ Inpatient Expenditure

5-6 ADLs $\times$ Inpatient Expenditure

IADLs only $\times$ Physician Service Expenditure

1-2 ADLs $\times$ Physician Service Expenditure

3-4 ADLs $\times$ Physician Service Expenditure

5-6 ADLs $\times$ Physician Service Expenditure

Factor loading on permanent heterogeneity, $\rho$

$(0.117)$

0.049
$(0.009)$

$0.169 \quad * *$

$(0.034)$

$0.180 \quad * *$

$(0.082)$

0.203

$(0.117)$

$0.046 \quad * *$

$(0.009)$

$0.154 \quad * *$

$(0.033)$

$0.341 \quad * *$

(0.081)

$1.232 \quad 1.516$

(1.004)

$(0.852)$

$4.224 \quad * *$

4.205

$(0.692)$

$7.783 \quad * *$

(0.620

$(0.871)$

9.286

(1.062)

7.849

$(0.778)$

9.221

$(0.815)$

$\begin{array}{lll}-0.207 & * & -0.212\end{array}$

$(0.116)$

$(0.113)$

$-0.101$

$-0.102$

$(0.098)$

$(0.097)$

0.037

0.039

$(0.126)$

$(0.123)$

$-0.029$

$-0.033$

(0.171)

(0.159)

$-0.022$

(0.047)

$-0.016$

$-0.056$

$(0.045)$

(0.037)

$-0.146$

(0.052)

$-0.055$

$-0.259$

(0.084)

0.292

(0.133)

$-0.144$

(0.049)

$-0.260$

(0.085)

0.253

(0.119)

$-0.012$

$-0.009$

(0.087)

(0.082)

$-0.165$

$-0.179$

(0.111)

(0.107)

0.041

0.052

(0.147)

(0.146)

- $\quad-0.199$

- $\quad(0.156)$

$-1.288 \quad * *$

Factor loading on time-varying heterogeneity, $\omega$

Note: Standard errors are in parentheses. ${ }^{* *}$ indicates joint significance at the $5 \%$ level; ${ }^{*} 10 \%$ level. Additional explanatory variables include individual demographic information. 
Health Care Utilization during period

Prescription Drug Expenditure

$\begin{array}{clccc}-0.186 & * * & -0.149 & \\ (0.084) & & (0.087) & \\ 0.053 & * * & 0.051 & * * \\ (0.007) & & (0.008) & \\ 0.136 & * * & 0.124 & * * \\ (0.024) & & (0.024) & \\ 0.156 & * * & 0.265 & * * \\ (0.058) & & (0.061) & \\ & & & \\ 3.067 & * * & 3.049 & * * \\ (0.569) & & (0.057) & \\ 5.134 & * * & 5.105 & * * \\ (0.472) & & (0.467) & \\ 8.894 & * * & 8.935 & * * \\ (0.710) & & (0.652) & \\ 8.190 & * * & 8.178 & * * \\ (0.989) & & (0.087) & \end{array}$

Interaction of Health Status and Utilization

Health Status at beginning of period

IADLs only

1-2 ADLs

3-4 ADLs

5-6 ADLs

IADLs only $\times$ Prescription Drug Expenditure

1-2 ADLs $\times$ Prescription Drug Expenditure

$-0.047$

$-0.052$

$(0.081)$

$(0.082)$

$-0.062$

$-0.067$

$(0.067)$

$(0.067)$

3-4 ADLs $\times$ Prescription Drug Expenditure

$-0.047$

$-0.047$

$(0.103)$

$(0.100)$

5-6 ADLs $\times$ Prescription Drug Expenditure

0.001

$(0.163)$

$-0.007$

$-0.037$

IADLs only $\times$ Inpatient Expenditure

$(0.031)$

$-0.082$

1-2 ADLs $\times$ Inpatient Expenditure

$(0.025)$

3-4 ADLs $\times$ Inpatient Expenditure

$-0.118$

5-6 ADLs $\times$ Inpatient Expenditure

(0.045)

$-0.237$

$(0.153)$

$-0.037$

$(0.031)$

$-0.081$

$(0.025)$

$-0.115$

$(0.042)$

$(0.083)$

$-0.237$

$-0.081$

$(0.071)$

$(0.083)$

IADLs only $\times$ Physician Service Expenditure

$-0.132$

1-2 ADLs $\times$ Physician Service Expenditure

$(0.060)$

$-0.292$

$(0.093)$

$-0.074$

$(0.070)$

3-4 ADLs $\times$ Physician Service Expenditure

$-0.112$

$-0.125$

$(0.060)$

$-0.301$

$(0.095)$

5-6 ADLs $\times$ Physician Service Expenditure

$(0.139)$

$-0.103$

$(0.142)$

Factor loading on permanent heterogeneity, $\rho$

$-0.341$

$(0.113)$

Factor loading on time-varying heterogeneity, $\omega$

$\begin{array}{ccc}- & -0.341 & * * \\ - & (0.113) & \\ - & -0.755 & * * \\ - & (0.207) & \end{array}$

Note: Standard errors are in parentheses. ${ }^{* *}$ indicates joint significance at the $5 \%$ level; ${ }^{*} 10 \%$ level. Additional explanatory variables include individual demographic information. 
Health Care Utilization during period

Prescription Drug Expenditure

\begin{tabular}{|c|c|c|}
\hline $\begin{array}{c}-0.057 \\
(0.037)\end{array}$ & & $\begin{array}{l}-0.047 \\
(0.038)\end{array}$ \\
\hline $\begin{array}{c}0.026 \\
(0.004)\end{array}$ & $* *$ & $\begin{array}{c}0.025 \\
(0.005)\end{array}$ \\
\hline $\begin{array}{c}0.066 \\
(0.012)\end{array}$ & $* *$ & $\begin{array}{c}0.062 \\
(0.013)\end{array}$ \\
\hline $\begin{array}{c}0.053 \\
(0.017)\end{array}$ & $* *$ & $\begin{array}{c}0.092 \\
(0.022)\end{array}$ \\
\hline $\begin{array}{c}2.193 \\
(0.185)\end{array}$ & $* *$ & $\begin{array}{c}2.193 \\
(0.188)\end{array}$ \\
\hline $\begin{array}{c}3.410 \\
(0.162)\end{array}$ & $* *$ & $\begin{array}{c}3.418 \\
(0.166)\end{array}$ \\
\hline $\begin{array}{c}5.516 \\
(0.573)\end{array}$ & $* *$ & $\begin{array}{c}5.588 \\
(0.530)\end{array}$ \\
\hline $\begin{array}{c}4.567 \\
(0.926)\end{array}$ & $* *$ & $\begin{array}{c}4.607 \\
(0.706)\end{array}$ \\
\hline
\end{tabular}

Interaction of Health Status and Utilization

Square of Prescription Drug Expenditure

Inpatient Care Expenditure

Physician Service Expenditure

\section{Health Status at beginning of period \\ IADLs only}

\section{1-2 ADLs}

3-4 ADLs

5-6 ADLs

IADLs only $\times$ Prescription Drug Expenditure

1-2 ADLs $\times$ Prescription Drug Expenditure

$-0.019 \quad-0.019$

$(0.030)$

(0.031)

$-0.034$

$-0.035$

$(0.026)$

$(0.027)$

3-4 ADLs $\times$ Prescription Drug Expenditure

$-0.022$

$-0.020$

$(0.086)$

$(0.083)$

5-6 ADLs $\times$ Prescription Drug Expenditure

0.010

$(0.159)$

0.007

$-0.013$

$(0.017)$

$-0.035$

$(0.015)$

$(0.148)$

IADLs only $\times$ Inpatient Expenditure

1-2 ADLs $\times$ Inpatient Expenditure

3-4 ADLs $\times$ Inpatient Expenditure

$-0.049$

$-0.013$

$(0.017)$

$-0.035$

$(0.015)$

$(0.041)$

$-0.049$

$-0.104$

(0.039)

5-6 ADLs $\times$ Inpatient Expenditure

IADLs only $\times$ Physician Service Expenditure

$(0.083)$

$-0.057$

$(0.024)$

$-0.052$

(0.022)

$-0.199$

$(0.077)$

$-0.094$

$(0.132)$

$-0.104$

$(0.084)$

$-0.057$

$(0.017)$

$-0.053$

$(0.015)$

$-0.214$

$(0.079)$

5-6 ADLs $\times$ Physician Service Expenditure

Factor loading on permanent heterogeneity, $\rho$

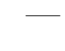

$-0.099$

$(0.125)$

$-0.121$

- $\quad(0.065)$

Factor loading on time-varying heterogeneity, $\omega$

$-0.230$

$(0.110)$

Note: Standard errors are in parentheses. ${ }^{* *}$ indicates joint significance at the $5 \%$ level; ${ }^{*} 10 \%$ level. Additional explanatory variables include individual demographic information. 


\section{Outcome: IADLs only}

Without Unobs'd

With Unobs'd

Heterogeneity

Heterogeneity

\section{Health Care Utilization during period \\ Prescription Drug Expenditure \\ Square of Prescription Drug Expenditure \\ Inpatient Care Expenditure \\ Physician Service Expenditure}

\section{Health Status at beginning of period \\ IADLs only}

\section{1-2 ADLs}

3-4 ADLs

5-6 ADLs

\section{Interaction of Health Status and Utilization}

IADLs only $\times$ Prescription Drug Expenditure

1-2 ADLs $\times$ Prescription Drug Expenditure

3-4 ADLs $\times$ Prescription Drug Expenditure

5-6 ADLs $\times$ Prescription Drug Expenditure

IADLs only $\times$ Inpatient Expenditure

1-2 ADLs $\times$ Inpatient Expenditure

3-4 ADLs $\times$ Inpatient Expenditure

5-6 ADLs $\times$ Inpatient Expenditure

IADLs only $\times$ Physician Service Expenditure

1-2 ADLs $\times$ Physician Service Expenditure

3-4 ADLs $\times$ Physician Service Expenditure

5-6 ADLs $\times$ Physician Service Expenditure

Factor loading on permanent heterogeneity, $\rho$

Factor loading on time-varying heterogeneity, $\omega$

$\begin{array}{ccccc}-0.074 & * * & -0.066 & * \\ (0.035) & & (0.036) & \\ 0.024 & * * & 0.023 & * * \\ (0.004) & & (0.004) & \\ 0.065 & * * & 0.060 & * * \\ (0.012) & & (0.013) & \\ 0.016 & & 0.057 & * * \\ (0.016) & & (0.020) & \end{array}$

$2.430 \quad * * \quad 2.426 \quad * *$

$(0.152)$

$1.694 \quad * * \quad 1.689 \quad * *$

$(0.187)$

$3.461 \quad * *$

$(0.659)$

$2.424 \quad * *$

(1.157)

$\begin{array}{ll}-0.021 & -0.020 \quad * *\end{array}$

$(0.026) \quad(0.026)$

$0.030 \quad 0.032$

(0.031) (0.031)

$0.046 \quad 0.050$

$(0.102) \quad(0.098)$

$0.052 \quad 0.052$

$(0.194) \quad(0.183)$

$-0.009 \quad-0.009$

$(0.160) \quad(0.016)$

$-0.014 \quad-0.013$

$(0.016) \quad(0.017)$

$0.009 \quad 0.012$

(0.047) (0.043)

$-0.171 \quad-0.172$

$(0.102) \quad(0.101)$

$-0.039 * \quad-0.039$ *

$(0.021) \quad(0.022)$

$-0.039 \quad-0.040$

$(0.025) \quad(0.025)$

$\begin{array}{lll}-0.229 \quad * * & -0.245 \quad * *\end{array}$

(0.086) (0.089)

$-0.012 \quad-0.011$

$(0.155) \quad(0.154)$

$-0.006$

$(0.070)$

$-0.302 \quad * *$

$(0.121)$

Note: Standard errors are in parentheses. ${ }^{* *}$ indicates joint significance at the $5 \%$ level; ${ }^{*} 10 \%$ level. Additional explanatory variables include individual demographic information. 
Table 6: Comparisons of Actual Observations and Model Predictions, by year

\begin{tabular}{|c|c|c|c|c|c|c|c|c|}
\hline Year & 1992 & 1993 & 1994 & 1995 & 1996 & 1997 & 1998 & Average \\
\hline \multicolumn{9}{|l|}{ Observations from MCBS } \\
\hline Probability of Prescription Drug Use & 0.88 & 0.88 & 0.88 & 0.89 & 0.88 & 0.90 & 0.92 & 0.89 \\
\hline Drug Expenditure, If Any & 564 & 608 & 655 & 702 & 756 & 826 & 943 & 714 \\
\hline Probability of Hospitalization & 0.17 & 0.20 & 0.19 & 0.19 & 0.19 & 0.19 & 0.21 & 0.19 \\
\hline Hospital Expenditure, If Any & 11,480 & 11,844 & 11,856 & 11,311 & 10,982 & 10,836 & 10,415 & 11,246 \\
\hline Physician Service Expenditure & 1,613 & 1,641 & 1,651 & 1,335 & 1,612 & 1,601 & 1,655 & 1,586 \\
\hline Probability of Death & 0 & 0.034 & 0.042 & 0.038 & 0.043 & 0.036 & 0.050 & 0.035 \\
\hline \# of observations & 5,574 & 6,379 & 6,544 & 5,965 & 5,910 & 6,314 & 4,191 & 40,877 \\
\hline \multicolumn{9}{|l|}{ Predictions from Preferred Model } \\
\hline Probability of Prescription Drug Use & 0.90 & 0.91 & 0.92 & 0.92 & 0.92 & 0.92 & 0.92 & 0.92 \\
\hline Drug Expenditure, If Any & 799 & 752 & 773 & 789 & 795 & 803 & 795 & 786 \\
\hline Probability of Hospitalization & 0.15 & 0.18 & 0.19 & 0.19 & 0.19 & 0.19 & 0.20 & 0.18 \\
\hline Hospital Expenditure, If Any & - & 11,671 & 12,166 & 12,215 & 12,119 & 12,088 & 12,186 & 12,074 \\
\hline Physician Care Expenditure & 1,430 & 1,533 & 1,877 & 1,917 & 1,939 & 1,897 & 2,007 & 1,800 \\
\hline Probability of Death & 0 & 0.047 & 0.038 & 0.028 & 0.035 & 0.027 & 0.038 & 0.030 \\
\hline \# of observations & 5,574 & 6,379 & 6,544 & 5,965 & 5,910 & 6,314 & 4,191 & 40,877 \\
\hline
\end{tabular}

Note: Observations in this table include only those observed and simulated to be alive in a particular year. By construction, everyone in 1992 survives because individuals contribute a minimum of two years of data to estimation. 
Table 7: Five-year Simulation of Health Care Expenditures and Health Outcomes

\begin{tabular}{|c|c|c|c|c|c|c|c|}
\hline & $\begin{array}{c}\text { No } \\
\text { Benefit }\end{array}$ & $\begin{array}{c}\text { Observed } \\
\text { Benefit }\end{array}$ & $\begin{array}{c}\% \\
\triangle^{*}\end{array}$ & $\begin{array}{c}\text { Medicaid } \\
\text { Benefit }\end{array}$ & $\begin{array}{l}\% \\
\triangle^{*}\end{array}$ & $\begin{array}{l}\text { Private } \\
\text { Benefit }\end{array}$ & $\begin{array}{c}\% \\
\triangle^{*}\end{array}$ \\
\hline \multicolumn{8}{|l|}{ With Unobs'd Heterogeneity } \\
\hline \multicolumn{8}{|l|}{ Health Care Expenditures } \\
\hline Prescription Drug Expenditure & 2,886 & 3,211 & 11.3 & 3,238 & 12.2 & 3,392 & 17.5 \\
\hline Hospital Expenditure & 8,771 & 8,828 & 0.6 & 8,853 & 0.9 & 8,888 & 1.4 \\
\hline Physician Service Expenditure & 8,827 & 9,021 & 2.2 & 9,055 & 2.5 & 9,140 & 3.5 \\
\hline \multicolumn{8}{|l|}{ Health Outcomes } \\
\hline Survival & 79.81 & 80.80 & 0.99 & 81.27 & 1.57 & 81.92 & 2.11 \\
\hline No I/ADLs & 54.6 & 53.4 & -1.2 & 53.2 & -1.4 & 52.6 & -2.0 \\
\hline IADLs Only & 15.3 & 15.5 & 0.2 & 15.5 & 0.2 & 15.6 & 0.3 \\
\hline 1-2 ADLs & 18.6 & 19.1 & 0.5 & 19.2 & 0.6 & 19.4 & 0.8 \\
\hline 3-4 ADLs & 6.3 & 6.6 & 0.3 & 6.7 & 0.4 & 6.8 & 0.5 \\
\hline 5-6 ADLs & 5.0 & 5.3 & 0.3 & 5.4 & 0.4 & 5.5 & 0.5 \\
\hline \multicolumn{8}{|l|}{ Without Unobs'd Heterogeneity } \\
\hline \multicolumn{8}{|l|}{ Health Care Expenditures } \\
\hline Prescription Drug Expenditure & 3,308 & 3,679 & 11.22 & 3,657 & 10.6 & 3,879 & 20.3 \\
\hline Hospital Expenditure & 9,141 & 9,251 & 1.20 & 9,258 & 1.3 & 9,294 & 1.7 \\
\hline Physician Service Expenditure & 9,736 & 10,145 & 4.20 & 10,174 & 4.5 & 10,398 & 6.8 \\
\hline \multicolumn{8}{|l|}{ Health Outcomes } \\
\hline Survival & 79.70 & 80.76 & 1.06 & 80.59 & 0.89 & 80.99 & 1.29 \\
\hline No I/ADLs & 54.3 & 53.1 & -1.2 & 52.9 & -1.4 & 52.3 & -2.0 \\
\hline IADLs Only & 15.3 & 15.5 & 0.2 & 15.5 & 0.2 & 15.5 & 0.2 \\
\hline 1-2 ADLs & 18.8 & 19.1 & 0.3 & 19.3 & 0.5 & 19.5 & 0.7 \\
\hline 3-4 ADLs & 6.5 & 6.8 & 0.3 & 6.8 & 0.3 & 7.0 & 0.5 \\
\hline 5-6 ADLs & 5.2 & 5.5 & 0.3 & 5.5 & 0.3 & 5.6 & 0.3 \\
\hline
\end{tabular}

Note: $* \% \triangle$ refers to percentage change when the outcome is in levels (expenditures) and percentage point change when the outcome is a percent (health). We report changes in behaviors from simulations of no drug coverage to the observed benefit structure (combinations of no supplemental coverage, Medicaid coverage, and private coverage of drugs), to a Medicaid-like benefit, and to a private insurance benefit, respectively. 
Table 8: Total Expenditures by five-year Health Status Transition

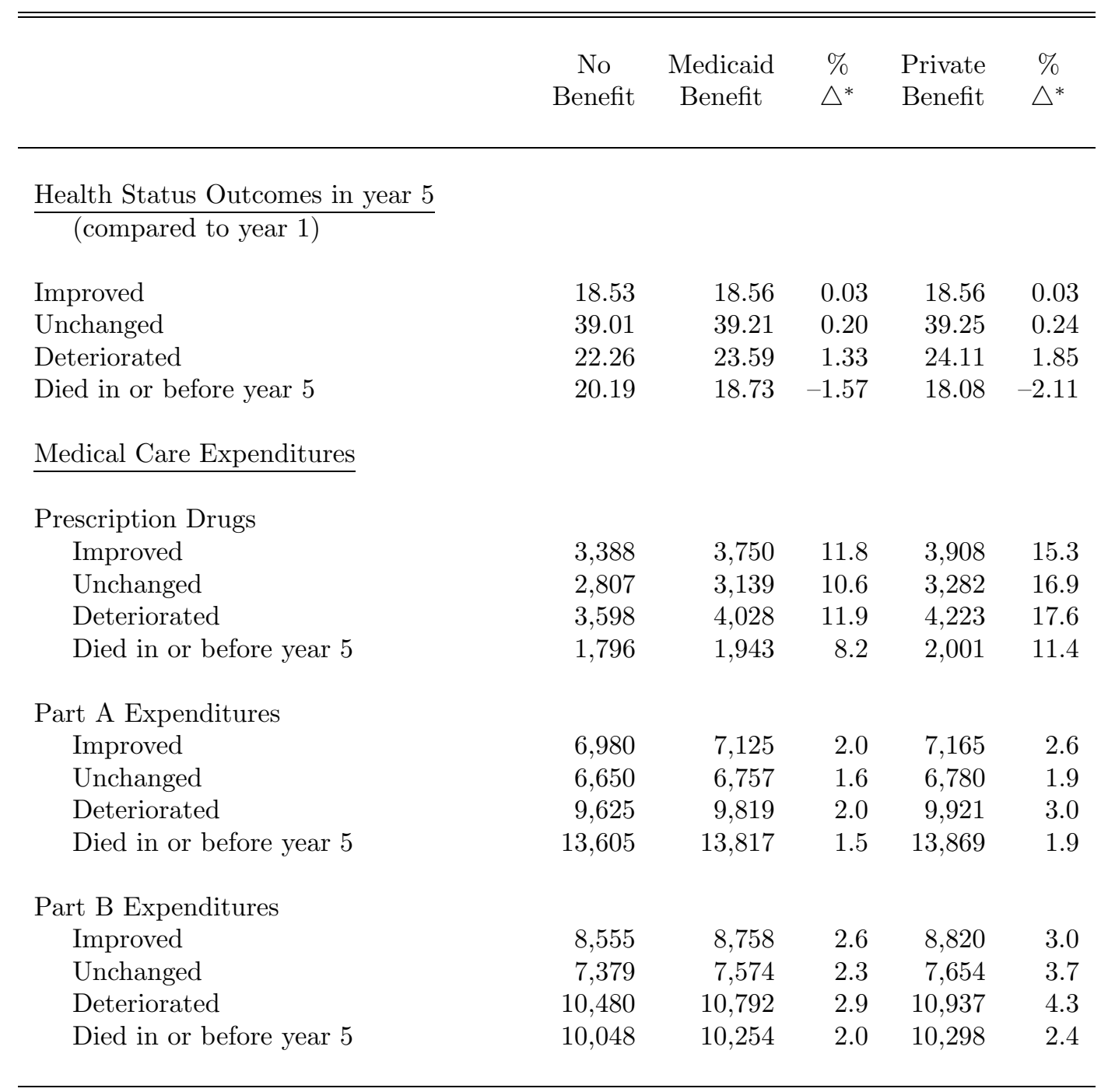

Note: $* \% \triangle$ refers to percentage change when the outcome is in levels (expenditures) and percentage point change when the outcome is a percent (health). 
Table 9: Total (five-year) Expenditures and 5th Year Health Outcomes (sole survivors vs. marginal survivors)

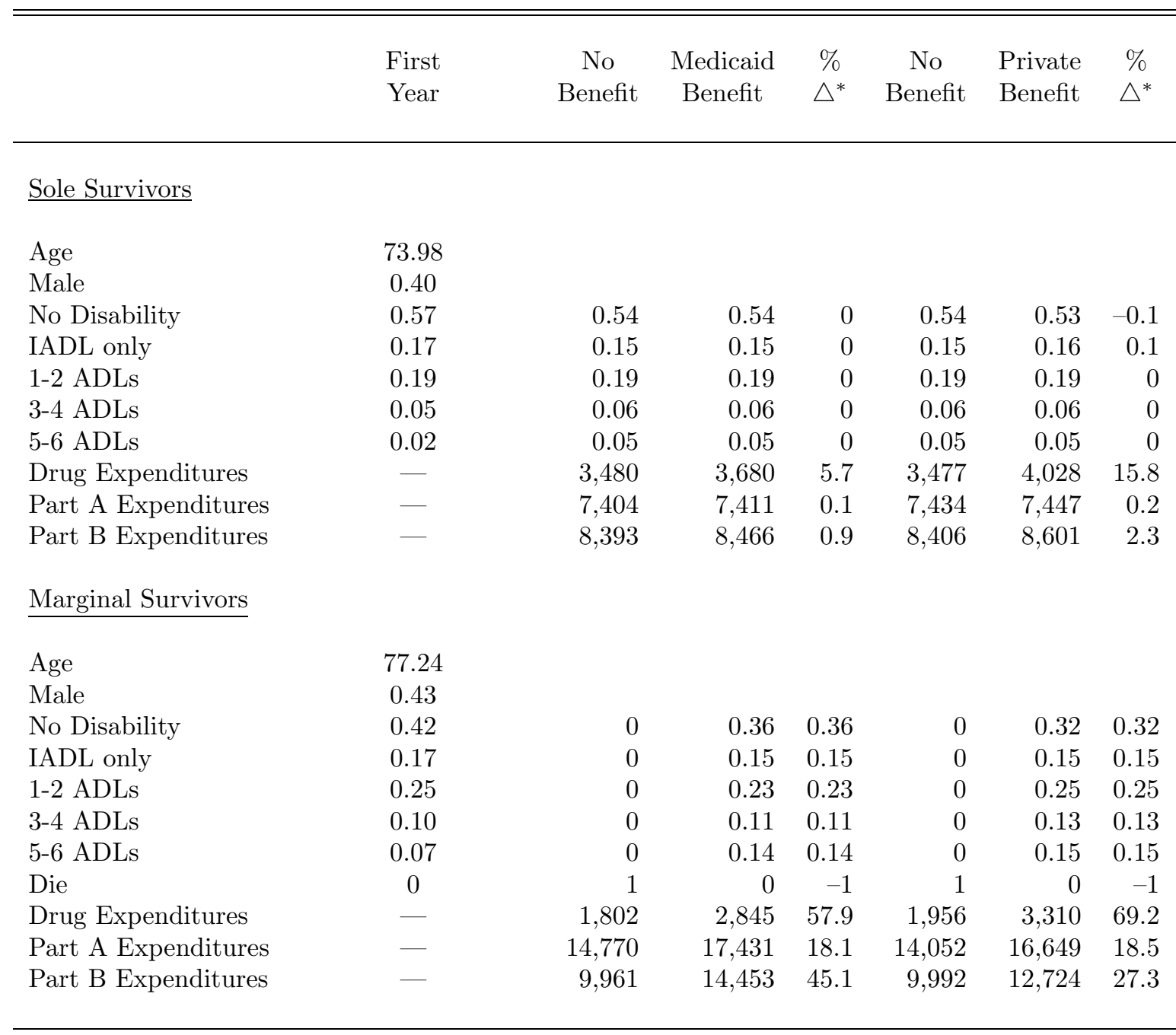

Note: $* \% \triangle$ refers to percentage change when the outcome is in levels (expenditures) and percentage point change when the outcome is a percent (health). Two different 'no benefit' columns are included because the composition of survivors is different across insurance simulations. 
Table 10: Immediate Effect of Drug Benefit

\begin{tabular}{|c|c|c|c|c|c|c|c|}
\hline & $\begin{array}{c}\text { No } \\
\text { Benefit }\end{array}$ & $\begin{array}{c}\text { Observed } \\
\text { Benefit }\end{array}$ & $\begin{array}{l}\% \\
\triangle^{*}\end{array}$ & $\begin{array}{c}\text { Medicaid } \\
\text { Benefit }\end{array}$ & $\begin{array}{l}\% \\
\triangle^{*}\end{array}$ & $\begin{array}{l}\text { Private } \\
\text { Benefit }\end{array}$ & $\begin{array}{l}\% \\
\triangle^{*}\end{array}$ \\
\hline \multicolumn{8}{|l|}{ With Unobs'd Heterogeneity } \\
\hline \multicolumn{8}{|l|}{ Health Care Expenditures } \\
\hline Prescription Drug Expenditure & 635 & 686 & 8.0 & 670 & 5.5 & 717 & 12.9 \\
\hline Hospital Expenditure & 2,305 & 2,305 & 0 & 2,305 & 0 & 2,306 & 0 \\
\hline Physician Service Expenditure & 1,610 & 1,610 & 0 & 1,610 & 0 & 1,610 & 0 \\
\hline \multicolumn{8}{|l|}{ Health Outcomes } \\
\hline Survival & 95.3 & 95.5 & 0.2 & 95.5 & 0.2 & 95.6 & 0.3 \\
\hline No I/ADLs & 52.8 & 52.5 & -0.3 & 50.7 & -0.1 & 52.4 & -0.3 \\
\hline IADLs Only & 16.1 & 16.1 & 0 & 16.1 & 0 & 16.1 & 0 \\
\hline 1-2 ADLs & 19.9 & 20.0 & 0.1 & 20.0 & 0.1 & 20.1 & 0.2 \\
\hline 3-4 ADLs & 6.7 & 6.8 & 0.1 & 6.8 & 0.1 & 6.9 & 0.2 \\
\hline 5-6 ADLs & 4.4 & 4.4 & 0 & 4.4 & 0 & 4.4 & 0 \\
\hline \multicolumn{8}{|l|}{ Without Unobs'd Heterogeneity } \\
\hline \multicolumn{8}{|l|}{ Health Care Expenditures } \\
\hline Prescription Drug Expenditure & 700 & 761 & 8.7 & 753 & 7.5 & 793 & 12.5 \\
\hline Hospital Expenditure & 2,365 & 2,367 & 0 & 2,367 & 0 & 2,367 & 0 \\
\hline Physician Service Expenditure & 1,540 & 1,540 & 0 & 1,540 & 0 & 1,540 & 0 \\
\hline \multicolumn{8}{|l|}{ Health Outcomes } \\
\hline Survival & 95.2 & 95.3 & 0.1 & 95.4 & 0.1 & 95.5 & 0.3 \\
\hline No I/ADLs & 52.8 & 52.5 & -0.3 & 52.5 & -0.3 & 52.4 & -0.4 \\
\hline IADLs Only & 16.0 & 16.2 & 0.2 & 16.1 & 0.1 & 16.1 & 0.1 \\
\hline 1-2 ADLs & 20.0 & 20.2 & 0.2 & 20.1 & 0.1 & 20.2 & 0.2 \\
\hline 3-4 ADLs & 6.7 & 6.8 & 0.1 & 6.8 & 0.1 & 6.9 & 0.2 \\
\hline 5-6 ADLs & 4.3 & 4.3 & 0 & 4.3 & 0 & 4.4 & 0.1 \\
\hline
\end{tabular}

Note: $* \% \triangle$ refers to percentage change when the outcome is in levels (expenditures) and percentage point change when the outcome is a percent (health).

We report changes in behaviors from simulations of no drug coverage to the observed benefit structure (combinations of no supplemental coverage, Medicaid coverage, and private coverage of drugs), to a Medicaid-like benefit, and to a private insurance benefit, respectively. 


\begin{tabular}{|c|c|c|c|}
\hline & Medicaid & $\begin{array}{c}\text { Other Insurance } \\
\text { With Drug Benefit }\end{array}$ & $\begin{array}{c}\text { Other Insurance } \\
\text { Without Drug Benefit }\end{array}$ \\
\hline Age & $\begin{array}{l}-0.07 \\
(0.10)\end{array}$ & $\begin{array}{l}0.25^{* *} \\
(0.09)\end{array}$ & $\begin{array}{l}0.39^{* *} \\
(0.09)\end{array}$ \\
\hline Age Squared & $\begin{array}{c}0.04 \\
(0.06)\end{array}$ & $\begin{array}{l}-0.17^{* *} \\
(0.06)\end{array}$ & $\begin{array}{l}-0.23^{* *} \\
(0.06)\end{array}$ \\
\hline Male & $\begin{array}{l}-0.72^{* *} \\
(0.11)\end{array}$ & $\begin{array}{l}-0.56^{* *} \\
(0.10)\end{array}$ & $\begin{array}{l}-0.76^{* *} \\
(0.10)\end{array}$ \\
\hline Race: Black & $\begin{array}{c}0.12 \\
(0.11)\end{array}$ & $\begin{array}{l}-1.20^{* *} \\
(0.09)\end{array}$ & $\begin{array}{l}-1.80^{* *} \\
(0.11)\end{array}$ \\
\hline Race: Hispanic & $\begin{array}{l}1.31^{* *} \\
(0.27)\end{array}$ & $\begin{array}{l}-0.71^{* *} \\
(0.30)\end{array}$ & $\begin{array}{l}-1.03^{* *} \\
(0.35)\end{array}$ \\
\hline Race: Other Nonwhite & $\begin{array}{l}1.04^{* *} \\
(0.21)\end{array}$ & $\begin{array}{l}-0.68^{* *} \\
(0.21)\end{array}$ & $\begin{array}{l}-0.71^{* *} \\
(0.23)\end{array}$ \\
\hline Years of Education & $\begin{array}{l}-0.11^{* *} \\
(0.01)\end{array}$ & $\begin{array}{l}0.10^{* *} \\
(0.01)\end{array}$ & $\begin{array}{l}0.06^{* *} \\
(0.01)\end{array}$ \\
\hline Rural Resident & $\begin{array}{l}-0.26^{* *} \\
(0.08)\end{array}$ & $\begin{array}{l}-0.84^{* *} \\
(0.07)\end{array}$ & $\begin{array}{l}-0.14^{*} \\
(0.07)\end{array}$ \\
\hline Income & $\begin{array}{l}-0.74^{* *} \\
(0.04)\end{array}$ & $\begin{array}{l}0.41^{* *} \\
(0.02)\end{array}$ & $\begin{array}{l}0.30^{* *} \\
(0.02)\end{array}$ \\
\hline Height (in inches) & $\begin{array}{l}-0.05^{* *} \\
(0.01)\end{array}$ & $\begin{array}{l}0.01 \\
(0.01)\end{array}$ & $\begin{array}{l}-0.01 \\
(0.01)\end{array}$ \\
\hline Previously Had Cancer & $\begin{array}{l}0.01 \\
(0.09)\end{array}$ & $\begin{array}{l}0.16^{* *} \\
(0.08)\end{array}$ & $\begin{array}{l}0.23^{* *} \\
(0.08)\end{array}$ \\
\hline Previously Had Diabetes & $\begin{array}{l}0.25^{* *} \\
(0.11)\end{array}$ & $\begin{array}{c}0.09 \\
(0.09)\end{array}$ & $\begin{array}{c}0.08 \\
(0.09)\end{array}$ \\
\hline Previously Had Heart Attack & $\begin{array}{c}0.20^{*} \\
(0.10)\end{array}$ & $\begin{array}{c}0.08 \\
(0.08)\end{array}$ & $\begin{array}{l}-0.04 \\
(0.10)\end{array}$ \\
\hline Previously Had Hardening Artery & $\begin{array}{l}-0.05 \\
(0.12)\end{array}$ & $\begin{array}{c}0.05 \\
(0.10)\end{array}$ & $\begin{array}{c}0.05 \\
(0.11)\end{array}$ \\
\hline Previously Had Hypertension & $\begin{array}{l}0.28^{* *} \\
(0.08)\end{array}$ & $\begin{array}{l}0.14^{* *} \\
(0.07)\end{array}$ & $\begin{array}{l}0.05 \\
(0.07)\end{array}$ \\
\hline Previously Had Other Heart Diseases & $\begin{array}{l}0.26^{* *} \\
(0.09)\end{array}$ & $\begin{array}{l}0.17^{* *} \\
(0.08)\end{array}$ & $\begin{array}{c}0.13 \\
(0.08)\end{array}$ \\
\hline Previously Had Lung Disease & $\begin{array}{l}0.40^{* *} \\
(0.11)\end{array}$ & $\begin{array}{l}-0.07 \\
(0.10)\end{array}$ & $\begin{array}{l}-0.15 \\
(0.10)\end{array}$ \\
\hline Previously Had Stroke & $\begin{array}{c}0.20^{*} \\
(0.12)\end{array}$ & $\begin{array}{l}-0.19^{*} \\
(0.10)\end{array}$ & $\begin{array}{l}-0.17 \\
(0.11)\end{array}$ \\
\hline Factor loading on permanent heterogeneity, $\rho$ & $\begin{array}{l}1.16^{* *} \\
(0.10)\end{array}$ & $\begin{array}{c}0.55^{* *} \\
(0.07)\end{array}$ & $\begin{array}{l}1.21^{* *} \\
(0.08)\end{array}$ \\
\hline
\end{tabular}

Note: Standard errors are in parentheses. ${ }^{* *}$ indicates joint significance at the $5 \%$ level; ${ }^{*} 10 \%$ level. The omitted outcome is no supplemental insurance of any kind. 
Table A2: Parameter Estimates Explaining Initial Health Care Expenditures

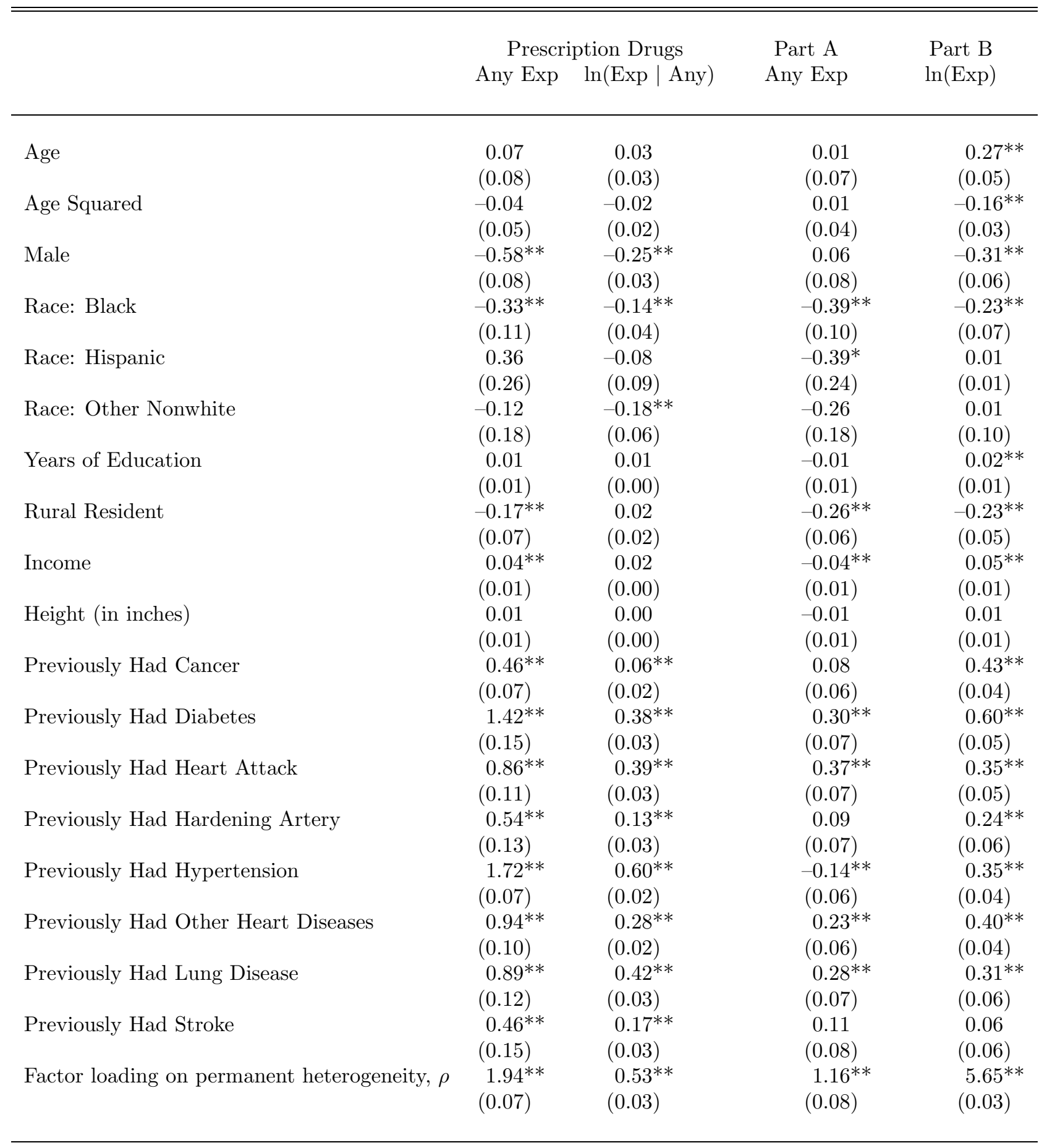

Note: Standard errors are in parentheses. ${ }^{* *}$ indicates joint significance at the $5 \%$ level; ${ }^{*} 10 \%$ level. 
Table A3: Parameter Estimates Explaining Initial Health

\begin{tabular}{|c|c|c|c|c|}
\hline & 5-6 ADLs & 3-4 ADLs & 1-2 ADLs & IADL only \\
\hline Age & $\begin{array}{l}-0.70^{* *} \\
(0.11)\end{array}$ & $\begin{array}{l}0.51^{* *} \\
(0.09)\end{array}$ & $\begin{array}{l}-0.40^{* *} \\
(0.07)\end{array}$ & $\begin{array}{c}-0.28^{* *} \\
(0.08)\end{array}$ \\
\hline Age Squared & $\begin{array}{l}0.53^{* *} \\
(0.07)\end{array}$ & $\begin{array}{l}0.40^{* *} \\
(0.06)\end{array}$ & $\begin{array}{c}0.31^{* *} \\
(0.05)\end{array}$ & $\begin{array}{l}0.23^{* *} \\
(0.05)\end{array}$ \\
\hline Male & $\begin{array}{l}-0.75^{* *} \\
(0.14)\end{array}$ & $\begin{array}{l}-0.84^{* *} \\
(0.11)\end{array}$ & $\begin{array}{l}-0.47^{* *} \\
(0.07)\end{array}$ & $\begin{array}{l}-0.76^{* *} \\
(0.08)\end{array}$ \\
\hline Race: Black & $\begin{array}{l}0.68^{* *} \\
(0.15)\end{array}$ & $\begin{array}{l}0.57^{* *} \\
(0.11)\end{array}$ & $\begin{array}{l}0.21^{* *} \\
(0.08)\end{array}$ & $\begin{array}{l}0.27^{* *} \\
(0.09)\end{array}$ \\
\hline Race: Hispanic & $\begin{array}{l}-0.44 \\
(0.44)\end{array}$ & $\begin{array}{c}0.02 \\
(0.29)\end{array}$ & $\begin{array}{l}-0.17 \\
(0.20)\end{array}$ & $\begin{array}{c}0.13 \\
(0.20)\end{array}$ \\
\hline Race: Other Nonwhite & $\begin{array}{c}0.31 \\
(0.28)\end{array}$ & $\begin{array}{l}-0.39 \\
(0.28)\end{array}$ & $\begin{array}{l}-0.05 \\
(0.16)\end{array}$ & $\begin{array}{c}0.23 \\
(0.15)\end{array}$ \\
\hline Years of Education & $\begin{array}{l}-0.12^{* *} \\
(0.01)\end{array}$ & $\begin{array}{l}-0.08^{* *} \\
(0.01)\end{array}$ & $\begin{array}{l}-0.07^{* *} \\
(0.01)\end{array}$ & $\begin{array}{l}-0.06^{* *} \\
(0.01)\end{array}$ \\
\hline Rural Resident & $\begin{array}{c}-0.12 \\
(0.11)\end{array}$ & $\begin{array}{c}0.13 \\
(0.08)\end{array}$ & $\begin{array}{l}0.14^{* *} \\
(0.05)\end{array}$ & $\begin{array}{c}0.01 \\
(0.06)\end{array}$ \\
\hline Height (in inches) & $\begin{array}{l}-0.01 \\
(0.01)\end{array}$ & $\begin{array}{l}-0.01 \\
(0.01)\end{array}$ & $\begin{array}{l}-0.01 \\
(0.01)\end{array}$ & $\begin{array}{c}0.01 \\
(0.01)\end{array}$ \\
\hline Previously Had Cancer & $\begin{array}{c}0.13 \\
(0.10)\end{array}$ & $\begin{array}{c}0.09 \\
(0.08)\end{array}$ & $\begin{array}{l}0.18^{* *} \\
(0.05)\end{array}$ & $\begin{array}{l}0.17^{* *} \\
(0.06)\end{array}$ \\
\hline Previously Had Diabetes & $\begin{array}{l}0.54^{* *} \\
(0.12)\end{array}$ & $\begin{array}{l}0.67^{* *} \\
(0.09)\end{array}$ & $\begin{array}{l}0.51^{* *} \\
(0.06)\end{array}$ & $\begin{array}{c}0.14^{*} \\
(0.07)\end{array}$ \\
\hline Previously Had Heart Attack & $\begin{array}{l}-0.06 \\
(0.11)\end{array}$ & $\begin{array}{l}0.26^{* *} \\
(0.09)\end{array}$ & $\begin{array}{l}0.22^{* *} \\
(0.06)\end{array}$ & $\begin{array}{l}0.28^{* *} \\
(0.06)\end{array}$ \\
\hline Previously Had Hardening Artery & $\begin{array}{l}0.59^{* *} \\
(0.12)\end{array}$ & $\begin{array}{l}0.63^{* *} \\
(0.09)\end{array}$ & $\begin{array}{l}0.33^{* *} \\
(0.07)\end{array}$ & $\begin{array}{l}0.25^{* *} \\
(0.08)\end{array}$ \\
\hline Previously Had Hypertension & $\begin{array}{l}-0.40 \\
(0.10)\end{array}$ & $\begin{array}{c}0.14^{*} \\
(0.08)\end{array}$ & $\begin{array}{l}0.11^{* *} \\
(0.05)\end{array}$ & $\begin{array}{c}0.03 \\
(0.05)\end{array}$ \\
\hline Previously Had Other Heart Diseases & $\begin{array}{c}0.47 \\
(0.10)\end{array}$ & $\begin{array}{l}0.35^{* *} \\
(0.08)\end{array}$ & $\begin{array}{l}0.30^{* *} \\
(0.05)\end{array}$ & $\begin{array}{l}0.26^{* *} \\
(0.06)\end{array}$ \\
\hline Previously Had Lung Disease & $\begin{array}{l}0.59^{* *} \\
(0.13)\end{array}$ & $\begin{array}{l}0.87^{* *} \\
(0.10)\end{array}$ & $\begin{array}{l}0.71^{* *} \\
(0.07)\end{array}$ & $\begin{array}{l}0.59^{* *} \\
(0.07)\end{array}$ \\
\hline Previously Had Stroke & $\begin{array}{l}1.79^{* *} \\
(0.12)\end{array}$ & $\begin{array}{l}1.17^{* *} \\
(0.10)\end{array}$ & $\begin{array}{l}0.64^{* *} \\
(0.08)\end{array}$ & $\begin{array}{l}0.54^{* *} \\
(0.09)\end{array}$ \\
\hline Factor loading on permanent heterogeneity, $\rho$ & $\begin{array}{l}-1.85^{* *} \\
(0.32)\end{array}$ & $\begin{array}{l}-0.87^{* *} \\
(0.14)\end{array}$ & $\begin{array}{l}-0.65^{* *} \\
(0.09)\end{array}$ & $\begin{array}{l}-0.10 \\
(0.09)\end{array}$ \\
\hline
\end{tabular}

Note: Standard errors are in parentheses. ${ }^{* *}$ indicates joint significance at the $5 \%$ level; ${ }^{*} 10 \%$ level. The omitted outcome is no I/ADLs. 